\title{
Effect of Molecular Architecture on Cell Interactions and Stealth Properties of PEG
}

\author{
Imran Ozer, ${ }^{\dagger, \downarrow, \S}$ Aysel Tomak,, Hadi M. Zareie, ${ }^{\|, \perp}$ Yusuf Baran, $\#, \bigcirc$ and Volga Bulmus $*, \dagger, \ddagger \odot$
}

${ }^{\dagger}$ Department of Bioengineering, ${ }^{\ddagger}$ Biotechnology and Bioengineering Graduate Program, "Department of Materials Science and Engineering, and ${ }^{\#}$ Department of Molecular Biology and Genetics, Izmir Institute of Technology, Urla, Izmir 35430, Turkey

${ }^{\perp}$ School of Mathematical and Physical Sciences, University of Technology Sydney, Ultimo, Sydney NSW 2007, Australia

ODepartment of Molecular Biology and Genetics, Abdullah Gul University, Kayseri 38080, Turkey

\section{Supporting Information}

ABSTRACT: PEGylation, covalent attachment of PEG to therapeutic biomolecules, in which suboptimal pharmacokinetic profiles limiting their therapeutic utility are of concern, is a widely applied technology. However, this technology has been challenged by reduced bioactivity of biomolecules upon PEGylation and immunogenicity of PEG triggering immune response and abrogating clinical efficacy, which collectively necessitate development of stealth polymer alternatives. Here we demonstrate that comb-shape poly[oligo(ethylene glycol) methyl ether methacrylate] (POEGMA), a stealth polymer alternative, has a more compact structure than PEG and self-organize into nanoparticles in a molecular weight dependent manner. Most notably, we show that combshape POEGMA promotes significantly higher cellular uptake and exhibits less steric hindrance imposed on the conjugated biomolecule than PEG. Collectively, comb-shape POEGMA offers a versatile alternative to PEG for stealth polymer-biomolecule conjugation applications.

\section{INTRODUCTION}

Biomolecular therapeutics have been increasingly used in the treatment of diseases. However, the suboptimal pharmacokinetic profiles of biomolecules, except antibodies, albumin, and transferrin, ${ }^{1}$ limit their utility as therapeutic reagents. ${ }^{2}$ Covalent attachment of polyethylene glycol (PEG) to biomolecules, "PEGylation", is one of the most widely used technologies to overcome intrinsic pharmacokinetic limitations of therapeutic biomolecules owing to its "stealth" properties. ${ }^{3-8}$ However, PEGylation usually results in reduced bioactivity by masking conjugated biomolecules with a hydrated polymeric cloud. ${ }^{9-11}$ In addition, the presence of anti-PEG antibodies has been reported in the clinical trials of several PEGylated therapeutic agents $^{12-15}$ and even in PEGylated therapeutic agent-naive individuals. ${ }^{16,17}$ Consequently, these attributes of PEG have led the researchers to search for better stealth polymer alternatives.

Recently, a comb-shape PEG-like polymer, poly(oligo(ethylene glycol) methyl ether (meth)acrylate (POEG(M)A), which consists of a number of hydrophilic PEG oligomer chains grafted to a hydrophobic poly(meth)acrylate backbone, has been suggested as a viable alternative to the gold standard PEG. The comb-shape POEGMA has been reported to improve pharmacokinetic properties of protein and peptide conjugates, $^{18,19}$ enhance stability and gene silencing efficiency of siRNAs, $^{20}$ and, most intriguingly, eliminate PEG antigenicity. ${ }^{1}$ However, an extensive analysis on the effect of architecture on harnessing these features remains to be investigated.

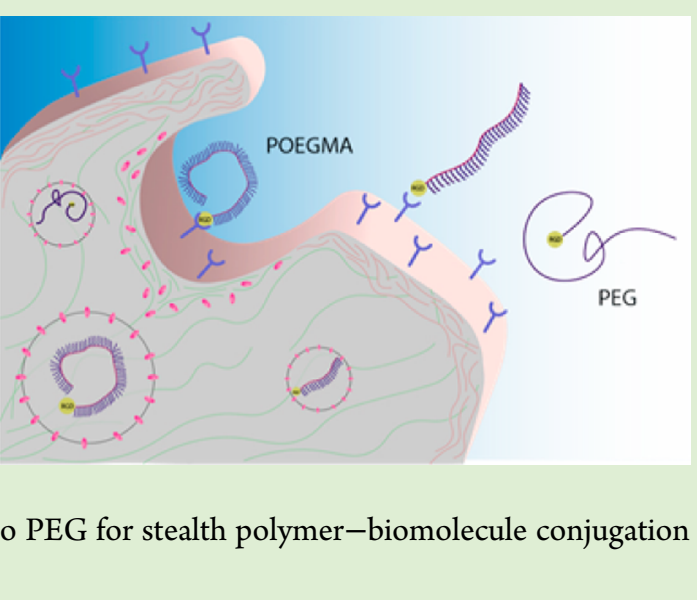

Herein, we compare comb-shape POEGMA with linear PEG in terms of physicochemical properties (i.e., size, molecular conformation), in vitro cell interaction profiles and steric hindrance imposed on the conjugated biomolecules. For this purpose, POEGMAs at two different molecular weights within the hydrodynamic size range of renal clearance were synthesized and characterized in terms of their molecular conformation and hydrodynamic size in various solutions along with their linear PEG counterparts at the same molecular weights. The cytotoxicity profile, the effect on the cell membrane integrity, cellular uptake profile, and cellular uptake mechanism of POEGMAs were investigated in cancerous and healthy cell lines and compared with those of the PEG counterparts. Finally, to determine the possible differences in the steric hindrance imposed by POEGMA or PEG on biomolecules, RGD peptide conjugates of both polymers were synthesized and compared in terms of integrin targeting efficiencies. It is important to note, however, that this study is of fundamental nature and does not aim to mimic in vivo conditions in which PEG and POEGMA are utilized or to find an eventual correlation with in vivo performances of PEG and POEGMA conjugates.

Received: March 28, 2017

Revised: July 31, 2017

Published: August 4, 2017 


\section{EXPERIMENTAL SECTION}

Synthesis of POEGMA via RAFT Polymerization. Poly(oligo(ethylene glycol)) methyl ether methacrylate (POEGMA) was synthesized according to the procedures reported elsewhere. ${ }^{20,21}$ Briefly, oligo(ethylene glycol) methyl ether methacrylate (OEGMA, number-average molecular weight $\left.\left(M_{\mathrm{n}}\right) 475 \mathrm{Da}\right)$ monomer $(4.75 \mathrm{~g}, 10$ $\mathrm{mmol})$, 4-cyano-4-(phenylcarbonothioylthio) pentanoic acid (0.0556 g, $0.2 \mathrm{mmol}$ ), and 2,2 azobis(isobutyronitrile) $(8.2 \mathrm{mg}, 0.05 \mathrm{mmol})$ were dissolved in acetonitrile $(10 \mathrm{~mL})$ in a Schlenk flask and the resulting solution was purged with nitrogen for $30 \mathrm{~min}$ on ice bath. Then, polymerization was initiated by immersion of the flask into an oil bath at $65{ }^{\circ} \mathrm{C}$ and continued for 140 or $225 \mathrm{~min}$ to obtain POEGMA $_{10 \mathrm{~K}}$ and POEGMA ${ }_{20 \mathrm{~K}}$, respectively. The solvent was partially removed under vacuum and the resulting mixture was purified via dialysis against ultrapure water for 5 days using dialysis tubing with molecular weight cutoff (MWCO) 3500 or cold diethyl ether precipitation, yielding pure POEGMA ${ }_{10 \mathrm{~K}}$ and $\mathrm{POEGMA}_{20 \mathrm{~K}}$, respectively. The resulting polymers were characterized via nuclear magnetic resonance (NMR; Figure S1) and gel permeation chromatography (GPC; Figure 2). Table 1 shows weight-average molecular weight

Table 1. Physical Properties of POEGMAs Used in the Study ${ }^{a}$

$\begin{array}{ccccc}\text { polymer } & \begin{array}{c}M_{\text {wRALS-GPC }} \\ (\mathrm{Da})\end{array} & \begin{array}{c}M_{\text {nRALS-GPC }} \\ (\mathrm{Da})\end{array} & \text { PDI }_{\text {RALS-GPC }} & \begin{array}{c}M_{\mathrm{NMR}} \\ (\mathrm{Da})\end{array} \\ \text { POEGMA }_{10 \mathrm{~K}} & 9700 & 8860 & 1.12 & 8470 \\ \text { POEGMA }_{20 \mathrm{~K}} & 20300 & 17200 & 1.18 & 16100\end{array}$

${ }^{a}$ Properties of linear counterparts, PEGs, were determined from their manufacturers: PEG $_{10 \mathrm{~K}}\left(M_{\mathrm{n}} 10 \mathrm{kDa}, \mathrm{PDI}<1.08\right)$ and $\mathrm{PEG}_{20 \mathrm{~K}}\left(M_{\mathrm{n}} 20\right.$ $\mathrm{kDa}$, PDI < 1.08).

$\left(M_{\text {wRALS-GPC }}\right)$, number-average molecular weight $\left(M_{\text {nRALS-GPC }}\right)$, and polydispersity index (PDI: $M_{\mathrm{w}} / M_{\mathrm{n}}$ ) values measured by right-angle light scattering-gel permeation chromatography (RALS-GPC) and number-average molecular weight calculated by ${ }^{1} \mathrm{H}$ NMR end-group analyses $\left(M_{n N M R}\right)$ of polymers.

End-Group Modification of Polymers. The thiocarbonylthio end-group of RAFT-synthesized POEGMAs was cleaved in order to prevent possible cytotoxic effects ${ }^{22}$ via aminolysis reaction in the presence of excess amines, following a procedure reported elsewhere. $^{23,24}$ Briefly, POEGMA $10 \mathrm{~K}$ or POEGMA ${ }_{20 \mathrm{~K}}(0.01 \mathrm{mmol})$, hexylamine (HEA; $0.0133 \mathrm{~mL}, 0.1 \mathrm{mmol}$ ), and triethylamine (TEA; $0.0140 \mathrm{~mL}, 0.1 \mathrm{mmol})$ were dissolved in acetonitrile $(2.5 \mathrm{~mL})$ and the resulting solution was kept stirred under nitrogen atmosphere for $2 \mathrm{~h}$ at room temperature, yielding thiocarbonylthio end-group removed thiol end-group functional polymers. The resulting thiol end-group functional polymers were immediately purified via cold diethyl ether precipitation. End-group modification of the polymers was verified by ${ }^{1}$ H NMR spectroscopy (Figure S2).

Prior to toxicity assays, thiol end-group of RAFT-synthesized POEGMAs formed after aminolysis and linear PEGs (mPEG-SH) were stably capped by addition of an oligo(ethylene glycol) methyl ether acrylate unit following a protocol reported elsewhere. ${ }^{23}$ After end-group capping, the resulting polymers were purified via dialysis against ultrapure water for 5 days using dialysis tubing with MWCO 3500 .

Prior to in vitro cell uptake experiments, thiol end-group of both linear PEGs $\left(\mathrm{mPEG}_{10 \mathrm{~K} / 20 \mathrm{~K}}-\mathrm{SH}\right.$ and $\left.\mathrm{NH}_{2}-\mathrm{PEG}_{10 \mathrm{~K}}-\mathrm{SH}\right)$ and comb-shape POEGMAs was labeled with Oregon Green maleimide 488 or Cy3maleimide fluorescent dye. Briefly, thiol-ended polymer (100 mM) and TCEP $(4 \mathrm{M})$ were dissolved in phosphate buffer $(0.2 \mathrm{M}, \mathrm{pH} 7.4)$ to reduce possible disulfide bonds. Then, Oregon Green maleimide 488 or Cy3 maleimide fluorescent dye was added to the reduced polymer solution under stirring yielding a solution in which polymer and dye concentrations were 40 and $200 \mathrm{mM}$, respectively. The resulting solution was purged with nitrogen for $30 \mathrm{~min}$ and stirred for $2 \mathrm{~h}$ at room temperature followed by addition of fresh TCEP $(0.4 \mathrm{M})$ under nitrogen and overnight reaction. The resulting dye-polymer conjugate was purified via dialysis using MWCO 3500 dialysis tubing against ultrapure water for 5 days and then freeze-dried. The absence of unconjugated dye in the fluorescent dye conjugated polymer solution was confirmed by size exclusion chromatography (SEC). The Oregon Green 488 or Cy3 fluorescent dye conjugation to the polymers was then confirmed via UV-vis spectroscopy analyses (Figure S4) and the degree of conjugation was calculated according to the manufacturers' protocols (Molecular Probes, Oregon, U.S.A.) that follow Beer-Lambert Law $\left(A_{x}=\varepsilon_{x} x b x C\right)$, where $A$ is the absorbance at $501 \mathrm{~nm}$ or at $555 \mathrm{~nm}$ for Oregon Green 488 or Cy3, respectively, $\varepsilon$ is the extinction coefficient $\left(81000 \mathrm{M}^{-1} \mathrm{~cm}^{-1}\right.$ for Oregon Green 488 at $501 \mathrm{~nm}$, or $150000 \mathrm{M}^{-1} \mathrm{~cm}^{-1}$ for Cy3 at $555 \mathrm{~nm}$ (provided by manufacturers) $), b$ is the path length $(\mathrm{cm}), C$ is the concentration (M), and $x$ is the specific wavelength (501 nm for Oregon Green 488 or $555 \mathrm{~nm}$ for Cy3). The degree of Oregon Green 488 or Сy3 fluorescent dye conjugation to polymers were given in Tables $\mathrm{S} 1$ and S2.

The resulting Oregon Green 488 fluorescent dye conjugated polymers were utilized in experiments to determine energy-dependent cellular uptake of polymers, time- and dose-dependent cellular uptake of polymers, the effect of cytoskeleton components on the cellular uptake polymers, and endocytosis routes mediating cellular uptake of polymers as described below. The resulting $\mathrm{Cy} 3$ fluorescent dye conjugated polymers were utilized in RGD (cRGDyC) conjugation experiments as described below.

CRGDyC Conjugation. $\omega$-Fluorescent $(\mathrm{Cy} 3)$ labeled POEGMA ${ }_{10 \mathrm{~K}}$ $\left(M_{\mathrm{n}} 9975 \mathrm{Da} ; 15.4 \mathrm{mg}, 3 \mathrm{mM}\right), \mathrm{N}$-(3-(dimethylamino)propyl)- $\mathrm{N}$ ethylcarbodiimide hydrochloride (EDC; $1.48 \mathrm{mg}, 15 \mathrm{mM}$ ) and $\mathrm{N}$ hydroxysuccinimide (NHS; $1.78 \mathrm{mg}, 30 \mathrm{mM}$ ) were dissolved in phosphate buffer $(0.51 \mathrm{~mL}, 0.2 \mathrm{M}, \mathrm{pH} 5.5)$ and reacted for $15 \mathrm{~min}$. Then, ethylenediamine $(5.2 \mu \mathrm{L}, 150 \mathrm{mM})$ was added to the polymer solution in which the final $\mathrm{pH}$ was adjusted to 7.8. The resulting solution was reacted at room temperature for $4 \mathrm{~h}$ and then dialyzed against ultrapure water for 3 days using MWCO 3500 dialysis tubing followed by freeze-drying to obtain $\alpha$-amine-terminated, $\omega$-Сy3 fluorescent-labeled POEGMA $10 \mathrm{~K}$.

In the next step, $\alpha$-amine-terminated $\omega$-Cy3 fluorescent-labeled POEGMA $_{10 \mathrm{~K}}$ or linear $\mathrm{PEG}_{10 \mathrm{~K}}$ was reacted with $\mathrm{N}$ - $\gamma$-maleimidobutyryl-oxysuccinimide ester (GMBS) cross-linker bearing NHS-ester and maleimide end groups to yield $\alpha$-maleimide functional polymer chains. To do so, the cross-linker $(4.2 \mathrm{mg}, 40 \mathrm{mM})$ was dissolved in phosphate buffer $(0.5 \mathrm{M}, \mathrm{pH} 7.2)$ and reacted with amine-terminated linear $\mathrm{PEG}_{10 \mathrm{~K}}$ or $\mathrm{POEGMA}_{10 \mathrm{~K}}(15 \mathrm{mg}, 4 \mathrm{mM})$ for $45 \mathrm{~min}$. The unreacted GMBS was removed via desalting (Pierce Polyacrylamide Desalting Columns, 1.8K MWCO) using phosphate buffer at $\mathrm{pH} 5.5$ as mobile phase, yielding pure $\alpha$-maleimide functional polymers, which were then freeze-dried.

The resulting $\alpha$-maleimide terminated polymers $(14.5 \mathrm{mg}, 1 \mathrm{mM}$ ) were dissolved in phosphate buffer $(0.5 \mathrm{M}, \mathrm{pH} 7.2)$ containing cRGDyC peptide $(8.3 \mathrm{mg}, 10 \mathrm{mM})$ and TCEP $(4.3 \mathrm{mg}, 10 \mathrm{mM})$. The resulting solution was purged with nitrogen for $30 \mathrm{~min}$ and stirred for $2 \mathrm{~h}$, followed by the addition of fresh TCEP $(2.15 \mathrm{mg}, 5 \mathrm{mM})$ under a nitrogen atmosphere. The reaction was continued overnight, and the resulting polymer-peptide conjugate was purified via dialysis against ultrapure water for 5 days using MWCO 3500 membrane and then freeze-dried.

RGD conjugations to Cy3-labeled POEGMA $A_{10 \mathrm{~K}}$ and $\mathrm{PEG}_{10 \mathrm{~K}}$ were verified via UV-vis spectroscopy analyses (Figure 9) using wellestablished methods in the literature. Prior to UV-vis spectroscopy analyses, the absence of unconjugated RGD in the RGD-POEGMA ${ }_{10 \mathrm{~K}^{-}}$ Cy3 and RGD-PEG ${ }_{10 \mathrm{~K}}{ }^{-\mathrm{C} 3} 3$ polymer solutions was confirmed by SEC. Then, the RGD conjugation degree was calculated relative to the degree of $\mathrm{Cy} 3$ fluorescent dye labeling by following Beer-Lambert Law $\left(A_{x}=\varepsilon_{x} x b x C\right)$, where $A$ is the corrected absorbance deriving from the RGD moiety on the polymer at $280 \mathrm{~nm}$ (free from signal interference of Cy3-labeled polymer at $280 \mathrm{~nm}$ ), $\varepsilon$ is the extinction coefficient of RGD $\left(1280 \mathrm{M}^{-1} \mathrm{~cm}^{-1}\right.$ for cRGDyC (provided by the manufacturer), $b$ is the path length $(\mathrm{cm}), C$ is the concentration (M), and $x$ is the specific wavelength $(280 \mathrm{~nm}$ for RGD due to signal of 
tyrosine at $280 \mathrm{~nm}$ ). Finally, using the known Cy3 fluorescent labeling degree of the polymers given above, the RGD conjugation degree was calculated according to eq 1 . Table S2 shows RGD conjugation degrees of RGD-POEGMA ${ }_{10 \mathrm{~K}}-\mathrm{Cy} 3$ and RGD-PEG ${ }_{10 \mathrm{~K}}-\mathrm{Cy} 3$, which were further utilized in experiments to determine the effect of POEGMA and PEG on the integrin targeting efficiency of RGD conjugates as described below.

$$
\begin{aligned}
& \text { RGD conjugation degree }\left(\frac{\mathrm{mol} c(\mathrm{RGDyC})}{\mathrm{mol} \text { polymer }}\right)=\left(\frac{\mathrm{mol} c(\mathrm{RGDyC})}{\mathrm{mol} \mathrm{Cy} 3}\right) \\
& \times\left(\frac{\mathrm{mol} \mathrm{Cy} 3}{\text { mol polymer }}\right)
\end{aligned}
$$

Cell Culture Methods. BEAS-2B and A549 cells were cultured using DMEM and RPMI-1640 medium, respectively, supplemented with $10 \%$ fetal bovine serum (FBS) and $0.1 \%$ gentamicin at $37^{\circ} \mathrm{C}$ in a humidified $5 \% \mathrm{CO}_{2}$ atmosphere. Subculture was performed when the cells had $80-90 \%$ confluence using trypsin-EDTA. The experimental details of cell viability and membrane integrity experiments were given in SI.

Cell Uptake of Polymers. Energy-dependent cell uptake of Oregon Green 488 labeled polymers, time- and dose-dependent cellular uptake of Oregon Green 488 labeled polymers, the effect of cytoskeleton components on the cellular uptake of Oregon Green 488 labeled polymers, endocytosis routes mediating cellular uptake of Oregon Green 488 labeled POEGMAs and PEGs, the effect of POEGMA and PEG on the integrin targeting efficiency of RGDPOEGMA $_{10 \mathrm{~K}}-\mathrm{Cy} 3$ and RGD-PEG $10 \mathrm{~K}-\mathrm{Cy} 3$ were determined via flow cytometry analyses. Briefly, A549 and BEAS-2B cells were transferred to 12 -well plates at a concentration of $10^{5}$ cells per well a day prior to sample exposure and incubated overnight at $37{ }^{\circ} \mathrm{C}$ in a humidified $5 \%$ $\mathrm{CO}_{2}$ atmosphere. Fluorescent dye-labeled polymer stock solution (5 $\mathrm{mM}$ ) was prepared in PBS $(1 \times)$ and filtered through a prerinsed 0.22 $\mu \mathrm{m}$ syringe filter. The cellular uptake of polymers was investigated via incubating the cells with polymers at specified temperatures for specified durations. At the end of the incubation period, the cell culture medium was removed immediately and wells were washed with cold PBS twice on ice. The cells were then harvested by trypsinization and centrifuged for $5 \mathrm{~min}$ at $4{ }^{\circ} \mathrm{C}$. The supernatant was removed and the resulting pellet was resuspended in cold PBS $(200 \mu \mathrm{L})$. The cellular uptake of polymers was measured via flow cytometry (BD FACSCantoTM, BD Biosciences, San Jose, U.S.A.), equipped with Oregon Green solid state 488 laser and 530/30 filter configuration. Data from 10000 events per sample were collected and analyzed using FacsDiva software. \% Cellular uptake (i.e., the ratio of the number of cells that internalize the polymer to the total number of cells) and uptake intensity (i.e., total fluorescence intensity divided by the total number of cells) determined from flow cytometry data and then were normalized according to the fluorescent dye labeling degree of polymers.

Energy-Dependent Cell Uptake of Polymers. The energy dependency of cellular uptake was investigated via incubating the cells with Oregon Green 488 labeled polymers at either 4 or $37^{\circ} \mathrm{C}$. For this purpose, first, cell suspensions and polymer solutions were separately incubated at either 4 or $37^{\circ} \mathrm{C}$ for $1 \mathrm{~h}$ prior to the addition of polymers to cells to equilibrate the temperature. After the equilibration period, the polymer solutions were added into the wells preserving the temperature of solutions at specified values. The final polymer concentration was $25 \mu \mathrm{M}$. The final PBS content was lower than or equal to $0.5 \%(\mathrm{v} / \mathrm{v})$. The cells were incubated with polymers at specified temperatures for 1 or $3 \mathrm{~h}$. At the end of the incubation period, the flow cytometry procedure given above was followed.

Time- and Dose-Dependent Cellular Uptake of Polymers. The time- and dose- dependency of cell uptake of Oregon Green 488 labeled polymers were investigated via incubating the cells with polymers at varying concentrations $(12.5$ or $25 \mu \mathrm{M})$ for 1 or $3 \mathrm{~h}$ at 37 ${ }^{\circ} \mathrm{C}$ in a humidified $5 \% \mathrm{CO}_{2}$ atmosphere. The final PBS content was lower than or equal to $0.5 \%(\mathrm{v} / \mathrm{v})$. At the end of the incubation period, the flow cytometry procedure given above was followed.
Effect of Cytoskeleton Components on the Cellular Uptake of Polymers. To gain better understanding of uptake mechanism of polymers, cellular uptake experiments were performed in the presence of cytoskeleton inhibitors, which are nocodazole (Noc) and cytochalasin $\mathrm{D}(\mathrm{CytD})$. First, the noncytotoxic dose range of inhibitors was determined based on the results of cell viability and membrane integrity assays in which cells were incubated with varying concentrations of inhibitors without any polymers for $2 \mathrm{~h}$. No significant change in the membrane integrity was observed in the inhibitor concentration range studied (data not shown). Based on the cell viability results (Figure S7), the working concentration of Noc and CytD was determined to be 20 and $10 \mu \mathrm{M}$ in both cell lines, respectively.

After determining noncytotoxic dose range of inhibitors, Oregon Green 488 labeled polymer uptake profiles of cells in the presence of inhibitors were determined. For this purpose, on the day of analysis, the cells were first treated with the inhibitor(s) for $1 \mathrm{~h}$ prior to polymer addition to promote cytoskeleton inhibition. The polymer solution was then added into the wells followed by $1 \mathrm{~h}$ incubation at $37^{\circ} \mathrm{C}$. The final polymer concentration was $12.5 \mu \mathrm{M}$. Note that the inhibitor concentration remained constant after polymer addition. The final PBS content was equal to or lower than $0.5 \%(\mathrm{v} / \mathrm{v})$. At the end of the incubation period, the flow cytometry procedure given above was followed.

Endocytosis Routes Mediating Cellular Uptake of POEGMAs and PEGs. To gain better understanding of the uptake mechanism of POEGMAs and PEGs, CDE and CME pathways were inhibited in the presence of chlorpromazine (CPZ) and genistein (GEN), respectively. First, the noncytotoxic dose ranges of inhibitors were determined via cell viability and membrane integrity assays in which cells were incubated with varying concentrations of inhibitors without any polymers for $2 \mathrm{~h}$. The cell viability was found to be above 50\% (Figure S8) and no significant change in the membrane integrity was observed in the inhibitor concentration range studied (data not shown).

After determining noncytotoxic dose range of inhibitors, the noncytotoxic minimum dose required to inhibit the specific endocytosis route was determined based on the uptake profile of pathway-specific marker molecules in the presence of inhibitors. To do so, A549 and BEAS-2B cells were incubated at various concentrations of CPZ and GEN within the noncytotoxic dose range for $1 \mathrm{~h}$ at $37^{\circ} \mathrm{C}$ in a humidified atmosphere followed by addition of pathway-specific marker molecules, which were transferrin from human serum (hTf) AlexaFluor 647 conjugate $\left(2 \mu \mathrm{g} \mathrm{mL} \mathrm{m}^{-1}\right)$ or BODIPY FL C5lactosylceramide complexed to BSA $(1 \mu \mathrm{M})$, respectively, and incubation for an additional hour. hTf is known to be specifically internalized via the CDE pathway, thus considered to be one of the markers of the CDE pathway. ${ }^{25,26}$ Lactosylceramide, on the other hand, a glycosphingolipid that resides in lipid rafts, is considered to be one of the best-characterized cargo molecules of the CME pathway and its cellular uptake is reported to be a direct evidence of the presence of caveola. ${ }^{25,26}$ At the end of the incubation period, the flow cytometry procedure given above was followed to determine the inhibition efficiencies of $\mathrm{CDE}$ and CME pathways. The uptake profile of pathway-specific marker molecules was shown in Figure S9 and inhibition efficiencies of CDE and CME pathways were given in Table S3. Overall, the optimum dose of CPZ and GEN was determined to be $100 \mu \mathrm{M}$ and $2 \mathrm{mM}$ for both cell lines, respectively.

To investigate the role of macropinocytosis, which is a subtype of endocytosis, on mediating the uptake of polymers, the working concentration range of 5-( $N$-ethyl- $N$-isopropyl) amiloride (EIPA), which inhibits macropinocytosis by lowering the submembranous $\mathrm{pH}$, was determined by following the protocol described above at the EIPA concentration range of $0-200 \mu \mathrm{M}$ (Figure S10a). FITC-dextran (70 $\mathrm{kDa}$ ) was used as pathway-specific marker, which is known to be internalized only via macropinocytosis due to its large hydrodynamic size, at a concentration of $3 \mathrm{mg} / \mathrm{mL}$ to determine inhibition profile of macropinocytosis at known concentrations of EIPA (Figure S10b). ${ }^{27}$

After determining the working concentration of CPZ and GEN, the cellular uptake profiles of Oregon Green 488 labeled POEGMAs and PEGs were determined in the presence of given concentrations of 
inhibitors. To do so, on the day of analysis, the cells were first treated with the inhibitor(s) for $1 \mathrm{~h}$ prior to polymer addition to promote endocytosis inhibition. The polymer solution was then added into the wells followed by a $1 \mathrm{~h}$ incubation at $37{ }^{\circ} \mathrm{C}$. The final polymer concentration was $12.5 \mu \mathrm{M}$. Note that the inhibitor concentration remained constant after polymer addition. The final PBS content was equal to or lower than $0.5 \%(\mathrm{v} / \mathrm{v})$. At the end of the incubation period, the flow cytometry procedure given above was followed.

Effect of POEGMA and PEG on the Integrin Targeting Efficiency of RGD Conjugates. The steric hindrance imposed on the integrin-targeting RGD moiety by POEGMA and PEG was compared. To do so, A549 and BEAS-2B cells, which are both known to express a wide range of integrin receptors on their surface ${ }^{28,29}$ were used for determining the effect of polymer architecture on integrin targeting efficiency of RGD. To do so, on the day of analysis, the cells were incubated in the presence of $25 \mu \mathrm{M}$ RGD-POEGMA ${ }_{10 \mathrm{~K}}-\mathrm{Cy} 3$ (RGD-POEGMA), RGD-PEG ${ }_{10 \mathrm{~K}}$-Cy3 (RGD-PEG), and only Cy3labeled POEGMA or PEG (without RGD) for $1 \mathrm{~h}$ at $37^{\circ} \mathrm{C}$, followed by flow cytometry analyses, as described above.

Analytical Techniques and Physicochemical Characterization Methods. Gel Permeation Chromatography. A Malvern BIYOM Viscotek gel permeation chromatography system equipped with a triple detector array, which consists of integrated refractive index, viscometer and right-angle light scattering detectors, and TSK Gel G3000PW $\mathrm{XL}_{\mathrm{XL}}$ column was used to characterize molecular weight $\left(M_{\mathrm{w}}\right.$ and $\left.M_{\mathrm{n}}\right)$ and molecular weight distribution (PDI) of polymers. POEGMA samples were dissolved in ultrapure water at $2 \mathrm{mg} \mathrm{mL}$ concentration and filtered through a prerinsed $0.1 \mu \mathrm{m}$ syringe filter. The injection volume was $100 \mu \mathrm{L}$. PBS (0.02 M sodium phosphate, $0.15 \mathrm{M} \mathrm{NaCl}, 0.05 \% \mathrm{NaN}_{3}$ ) was used as mobile phase at a flow rate of $0.8 \mathrm{~mL} \mathrm{~min}{ }^{-1}$. The calibration was performed using poly(ethylene oxide) (PEO) standards provided by Malvern.

UV-Vis Spectroscopy. A Thermo Scientific Evolution 201 UV-vis spectrophotometer was used to determine the fluorescent dye attachment to polymers at scanning mode in the range between 350 and $600 \mathrm{~nm}$ using quartz cuvettes. A Varioskan Flash microplate reader (Thermo Electron Corporation, Finland) was used to measure the absorbance values in a 96-well-plate in MTT and LDH assays.

NMR Spectroscopy. NMR spectroscopy was used to determine the chemical structure, purity and molecular weight $\left(M_{\mathrm{nNMR}}\right)$ of the synthesized polymers. ${ }^{1} \mathrm{H}$ NMR spectra were recorded on a Varian VNMRJ 400 spectrometer at Izmir Institute of Technology, Izmir. For NMR analyses, polymer samples were dissolved in deuterated chloroform $\left(\mathrm{CDCl}_{3}\right)$ or deuterium oxide $\left(\mathrm{D}_{2} \mathrm{O}\right)$ at $10 \mathrm{mg} \mathrm{m} \mathrm{m}^{-1}$ concentration. ACD/SpecManager software was used to analyze NMR spectra.

Dynamic Light Scattering (DLS). The hydrodynamic diameter $\left(D_{\mathrm{h}}\right)$ of polymers was measured via dynamic light scattering (DLS) analysis. The $D_{\mathrm{h}}$ of comb-shape POEGMAs was analyzed after aminolysis and stably capping of the resulting thiol end-group by addition of an oligo(ethylene glycol) methyl ether acrylate unit. Similarly, the $D_{\mathrm{h}}$ of linear PEGs was measured after capping of the thiol end-group by following the same procedure. PEG and POEGMA solutions (0.05 $\mathrm{mM}$ ) were prepared in prefiltered ultrapure water, $1 \times$ phosphate buffer ( $\mathrm{pH}$ 7.2) or phenol red-free cell culture medium with or without $10 \%$ serum. The resulting solutions were filtered through a prerinsed $0.1 \mu \mathrm{m}$ syringe filter immediately before DLS analyses. In order to prevent the interfering effect of serum proteins, polymers to be analyzed were incubated in serum containing phenol red-free cell culture medium or PBS overnight $(1 \mathrm{M})$ and diluted into water $(0.05$ M) followed by filtering through a prerinsed $0.1 \mu \mathrm{m}$ syringe filter just before the DLS analysis. The $D_{\mathrm{h}}$ of the polymers was measured using Zetasizer Nano ZS (Malvern, U.K.; measurement range $0.3 \mathrm{~nm}$ to 10.0 $\mu$ m; light source $\mathrm{He}-\mathrm{Ne}$ laser $633 \mathrm{~nm}$ Max $5 \mathrm{~mW}$; Power $100 \mathrm{VA}$ ) and Malvern disposable polystyrene low volume cuvettes at room temperature.

Atomic Force Microscopy (AFM). Linear PEGs or comb-shape POEGMAs, which were capped with an oligo(ethylene glycol) methyl ether acrylate unit through their thiol end-groups were dissolved in ultrapure water. Nanosurf EasyScan (Felx AFM) atomic force microscope operating in tapping mode in liquid was used to obtain topographic data. All imaging operations were conducted with $512 \times$ 512 data acquisitions at a various scan speed. NCLR tips with integrated cantilever having a nominal spring constant of $48 \mathrm{~N} / \mathrm{m}$ were used. For experiments, $\mathrm{Si}$ (111) substrates were used after cleaning with Piranha (CAUTION) solution. In a typical experiment, $\mathrm{Si}(111)$ substrate in ultrapure water was first scanned and then polymer solution ( $1 \mu \mathrm{M}$ in ultrapure water) was applied, followed by a waiting period of approximately $30 \mathrm{~min}$. A scan of approximately the same area was then performed. Images were manipulated using the scanning probe image processor (SPIP) software. Contrast-enhanced images were obtained by applying a correlation averaging procedure to analyze repeating molecular units and by applying low-pass filter.

Surface Plasmon Resonance (SPR). SPR Navi 200 system from BioNavis (Finland) with multiflow cells was used for SPR analyses. Gold sensor slides used in the system were purchased from BioNavis (Finland) and stored under nitrogen. Prior to use, the gold sensor slides were cleaned by immersing into a solution of sulfuric acid and hydrogen peroxide (3:1) for up to $1 \mathrm{~min}$. The slides were then rinsed thoroughly with pure water and absolute ethanol followed by rapid drying with nitrogen stream. The SPR analyses were carried out at a flow rate of $10 \mu \mathrm{L} / \mathrm{min}$ for $10 \mathrm{~min}$ using thiol-ended $\mathrm{PEG}_{10 \mathrm{~K}}$ or POEGMA $_{10 \mathrm{~K}}(0.05 \mathrm{mM})$ and $20 \%$ FBS solutions.

Statistical Analysis. Two-way analysis of variance (ANOVA) followed by post hoc Dunnett's multiple comparison test was employed for the statistical analysis of the obtained data and $p<$ 0.05 or $p<0.01$ values were considered to be statistically significant. The results of experiments, which were performed at least twice with at least three repeats, were expressed as mean \pm standard deviation.

\section{RESULTS AND DISCUSSION}

Considering the common use of linear PEGs having molecular weights in the range of $5-20 \mathrm{kDa}$ allowing renal clearance in therapeutic formulations, POEGMAs within this weightaverage molecular weight $\left(M_{\mathrm{w}}\right)$ range with low polydispersity (PDI) were synthesized via RAFT polymerization (POEG$\mathrm{MA}_{10 \mathrm{~K}} ; M_{\mathrm{w}} 9.7 \mathrm{kDa}$, PDI 1.12 and POEGMA $20 \mathrm{~K} ; M_{\mathrm{w}} 20.3 \mathrm{kDa}$, PDI 1.18; Figures 1, 2, and $S 1$ and Table 1). The linear counterparts of the polymers were obtained commercially $\left(M_{\mathrm{n}}\right.$ $10 \mathrm{kDa}$, PDI < $1.08\left(\mathrm{PEG}_{10 \mathrm{~K}}\right) ; M_{\mathrm{n}} 20 \mathrm{kDa}$, PDI $<1.08$ $\left.\left(\mathrm{PEG}_{20 \mathrm{~K}}\right)\right)$.
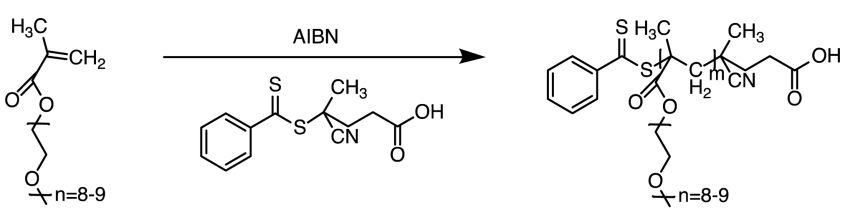

POEGMA

Figure 1. Synthesis of POEGMA. [Monomer]/[chain transfer agent]/ [initiator] = 200:4:1, acetonitrile, $65^{\circ} \mathrm{C}, 140 \mathrm{~min}\left(\mathrm{POEGMA}_{10 \mathrm{~K}}\right)$, and 225 min $\left(\right.$ POEGMA $\left._{20 \mathrm{~K}}\right)$.

Since the hydrodynamic size of polymers is one of the most important parameters determining their interactions with biological systems and in vivo fate, ${ }^{30,31}$ the number-average hydrodynamic diameter $\left(D_{\mathrm{h}}\right)$ of POEGMA and PEG in various media (water, phosphate buffer saline (PBS), and cell culture media with or without serum) at room temperature was investigated via dynamic light scattering (DLS) experiments (Figure 3$)$. The $D_{\mathrm{h}}$ of POEGMA $(2.84 \pm 1.20 \mathrm{~nm}$, POEGMA $_{10 \mathrm{~K}} ; 4.22 \pm 0.41 \mathrm{~nm}$, POEGMA $\left._{20 \mathrm{~K}}\right)$ was found to be significantly $(p<0.05)$ smaller than that of PEG $(6.69 \pm$ $\left.1.07 \mathrm{~nm}, \mathrm{PEG}_{10 \mathrm{~K}} ; 8.46 \pm 0.41 \mathrm{~nm}, \mathrm{PEG}_{20 \mathrm{~K}}\right)$ at equivalent molecular weight (MW) when water was used. This is expected since the branched structure of POEGMA has more compact 


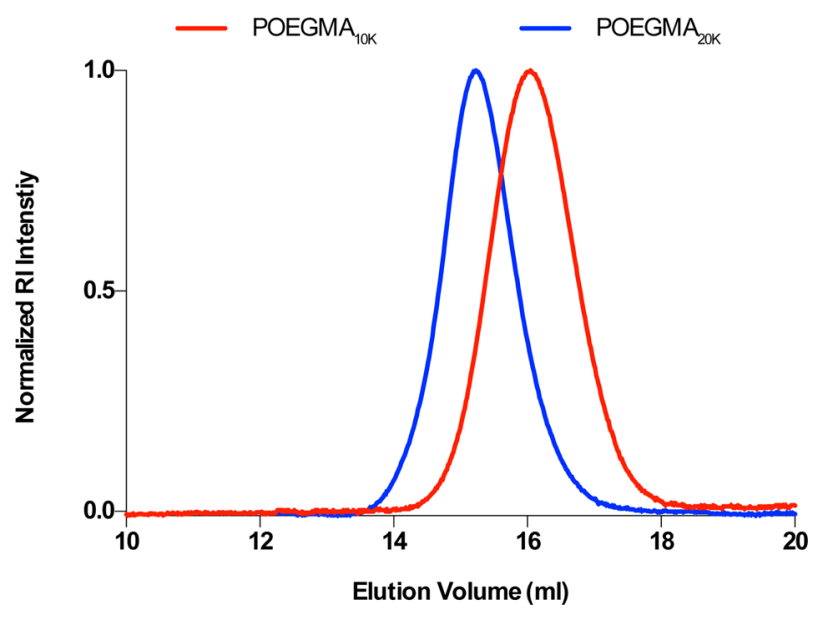

Figure 2. GPC chromatogram of POEGMA ${ }_{10 \mathrm{~K}}$ and POEGMA ${ }_{20 \mathrm{~K}}$.

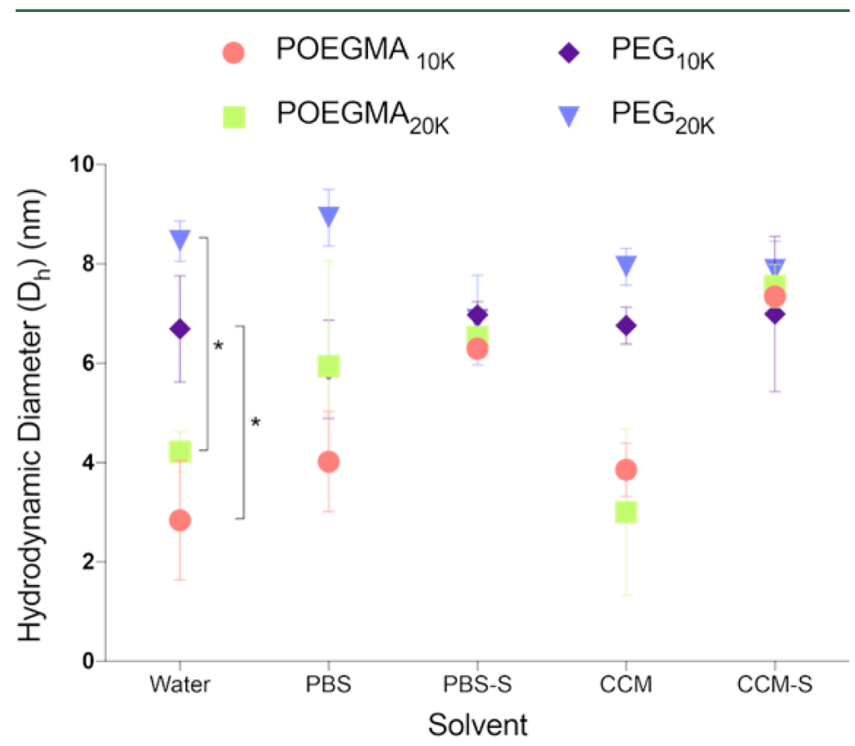

Figure 3. Hydrodynamic diameter $\left(D_{\mathrm{h}}\right)$ of comb-shape POEGMAs and linear PEGs (nm) (PBS: phosphate buffer saline, PBS-S: PBS containing 10\% serum, CCM: cell culture medium, CCM-S: CCM containing $10 \%$ serum). Data were analyzed by two-way ANOVA followed by post hoc Dunnett's multiple comparison test and plotted as mean \pm standard deviation, $n=12 ; * p<0.05$. conformation compared with the linear architecture. The $D_{\mathrm{h}}$ measurements of PEG chains were found to be in good agreement with literature values. ${ }^{32}$ It has been known that the MW of the polymers has a significant effect on $D_{\mathrm{h}}$; however, the MW did not seem to have any significant effect on the $D_{\mathrm{h}}$ of the polymers used in this study in the range studied $(p>0.05)$. In other words, the $D_{\mathrm{h}}$ of the polymers used in the study did not show any statistical difference in the MW range studied. In the case of PBS and cell culture media without serum, for both architectures and MW, no significant change in $D_{\mathrm{h}}$ occurred compared to those in water. It is expected that the presence of salts and charged compounds would not affect PEG or POEGMA chain conformation in solutions as both polymers have nonionizable and neutral chemical structure. It is important to note, however, that POEGMA shows temperature-responsive behavior and phase transitions above its lower critical solution temperature (LCST), and can be salted-out at high salt concentrations due to partial dehydration of the macromolecules. ${ }^{33,34}$ However, the effects observed in this study cannot be attributed to the phase-transition or salting-out of POEGMA. First, LCST of POEGMA with 8-9 ethylene glycol repeating units $\left(M_{\mathrm{w}}: 16800 \mathrm{~g} / \mathrm{mol}\right)$, which very closely resembles to the polymers used in this study, was estimated to be around $100{ }^{\circ} \mathrm{C}$ in $\mathrm{PBS}$, which was well above room temperature. ${ }^{33}$ Second, the salt concentration used in this study $(8 \mathrm{~g} / \mathrm{L})$ was lower than the salt concentration needed to saltout even a more hydrophobic form of POEGMA, a $\mathrm{P}\left(\mathrm{MEO}_{2} \mathrm{MA}\right.$-co-OEGMA $)$ copolymer, which is more than 12 $\mathrm{g} / \mathrm{L}$ at room temperature. ${ }^{34}$

On the other hand, the $D_{\mathrm{h}}$ of POEGMAs increased significantly $(p<0.05)$ when PBS or cell culture media containing $10 \%$ serum was used as a solvent, while there was no significant change in the $D_{\mathrm{h}}$ of PEGs revealing that comb-shape POEGMA differs significantly from PEG in terms of proteinrepellent properties (Figure 3). This result may be attributed to the existence of hydrophobic interactions between serum protein components and poly(methacrylate) backbone of comb-shape POEGMA.

To further investigate the interaction between comb-shape POEGMA and serum components, and to compare with that of linear PEG, SPR spectroscopy was used (Figure 4). For this purpose, thiol-terminated $\mathrm{PEG}_{10 \mathrm{~K}}$ or POEGMA $\mathrm{POK}_{10 \mathrm{~K}}$ solutions $(0.05 \mathrm{mM})$ were injected to the SPR cell at a flow rate of 10 $\mu \mathrm{L} / \mathrm{min}$ for $10 \mathrm{~min}$. First injection of polymer solutions caused
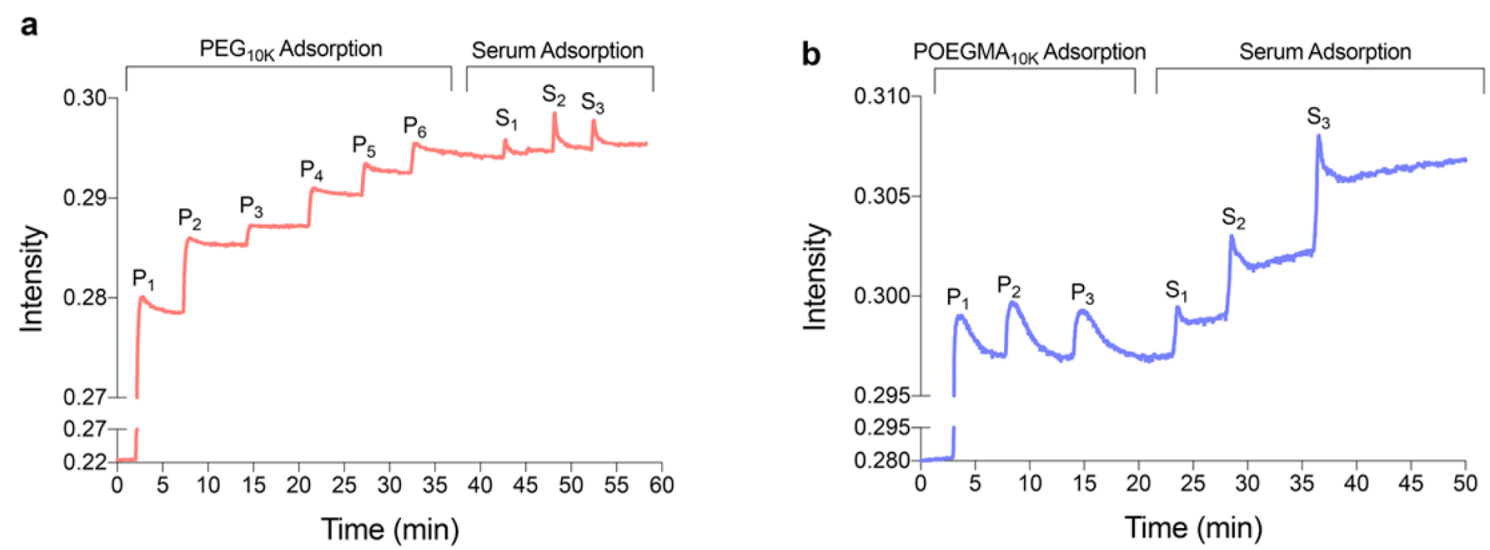

Figure 4. Surface plasmon resonance (SPR) spectroscopy analysis of the interaction of serum components with PEG $10 \mathrm{~K}$ (a) and POEGMA $10 \mathrm{~K}$ (b). $\mathrm{P}_{1-6}$ and $\mathrm{P}_{1-3}$ are polymer solution injections and $\mathrm{S}_{1-3}$ are $20 \%$ FBS solution injections. 
a sharp increase in the refractive index unit (RIU)), indicating binding of $\mathrm{PEG}_{10 \mathrm{~K}}$ or POEGMA $\mathrm{P}_{10 \mathrm{~K}}$ onto gold sensor slides $\left(\mathrm{P}_{1}\right.$ signals in Figure $4 a$ and $b$, respectively), followed by a slight decline in the signal due to the removal of unbound polymers during water rinse of SPR cell under continuous flow. PEG $_{10 \mathrm{~K}}$ was needed to be injected six times (P1-P6 in Figure 4a), whereas only three injections were needed for POEGMA ${ }_{10 \mathrm{~K}}$ $\left(\mathrm{P}_{1}-\mathrm{P}_{3}\right.$ in Figure $\left.4 \mathrm{~b}\right)$ to saturate the sensor surface with polymers. The refractive index unit (RIU) change was 0.070 and 0.016 for $\mathrm{PEG}_{10 \mathrm{~K}}$ and POEGMA ${ }_{10 \mathrm{~K}}$, respectively, possibly indicating a higher packing of linear $\mathrm{PEG}_{10 \mathrm{~K}}$ chains adsorbed on the surface when compared with the branched POEGMA ${ }_{10 \mathrm{~K}}$ chains. ${ }^{35}$ After forming $\mathrm{PEG}_{10 \mathrm{~K}}$ or POEGMA $10 \mathrm{~K}$ thin layer on the gold sensor slides, $20 \%$ FBS solution was injected at a flow rate of $10 \mu \mathrm{L} / \mathrm{min}$ for $10 \mathrm{~min}$ followed by water rinse at a flow rate of $10 \mu \mathrm{L} / \mathrm{min}$ for $10 \mathrm{~min}$. The serum injections and water rinses were repeated three times, which correspond to the peaks $S_{1}-S_{3}$ in Figure 4a,b. The interaction between serum and $\mathrm{PEG}_{10 \mathrm{~K}}$ thin layer was found to be insignificant, as the sensogram in Figure 4a showed no increase in the baseline signal upon repeated injections of serum. On the contrary, there was a significant increase in the baseline signal revealing the adsorption of serum components by POEGMA ${ }_{10 \mathrm{~K}}$ thin layer on the sensor slide. Therefore, it was concluded that the comb-shape POEGMA interacts with serum components, while PEG does not, supporting the DLS findings described above.

To investigate conformational differences between the POEGMA and PEG, AFM analyses were performed at liquid and dry phase (Figures 5 and S3). The AFM images of
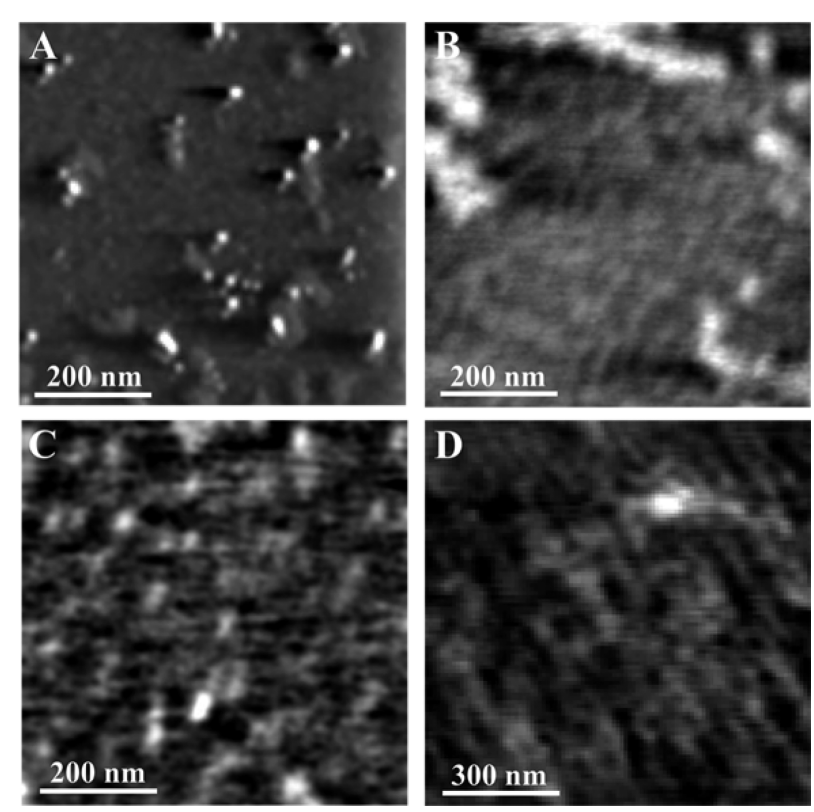

Figure 5. AFM micrographs of (a) POEGMA ${ }_{10 \mathrm{~K}}$, (b) POEGMA POK $_{2}$ (c) $\mathrm{PEG}_{10 \mathrm{~K}}$ and (d) $\mathrm{PEG}_{20 \mathrm{~K}}$ taken in tapping mode in liquid.

POEGMA and PEG taken in water revealed that POEGMA underwent intrachain self-organization into nanoparticles depending on the MW while PEG chains exist in a random conformation regardless of the MW. Lower MW POEGMA chains, POEGMA ${ }_{10 \mathrm{~K}}$ displayed self-organization into nanoparticles, while POEGMA ${ }_{20 \mathrm{~K}}$ did not. The average width of a single POEGMA $_{10 \mathrm{~K}}$ particle was about $17.5 \pm 1.7 \mathrm{~nm}$., which was larger than the $D_{\mathrm{h}}$ observed for the same polymer via DLS.
It should be noted that the tip broadening effect is usually observed in AFM measurements as a result of the finite size of the AFM tip with respect to the molecular width. The radius of curvature of the AFM tip is typically $10-30 \mathrm{~nm}$, which is almost $10-20 \times$ larger than the molecular width. As a result of this size mismatch, the profile which the tip traces out as it passes over the molecules is correspondingly broadened. The broadening was reported to be about 1-5-fold. ${ }^{36,37}$ Nanoparticles having an apparent diameter of $17.5 \pm 1.7 \mathrm{~nm}$ were observed in AFM images of POEGMA ${ }_{10 \mathrm{~K}}$, which corresponded to 6-fold of $D_{\mathrm{h}}$ determined by DLS $(2.84 \pm 1.20 \mathrm{~nm})$, suggesting the presence of tip broadening effect in AFM images. In summary, the AFM apparent size was in good accord with the size of a single polymer chain observed by DLS. The nanoparticle shape observed in AFM image revealed the intrachain self-organization behavior of POEGMA $10 \mathrm{~K}$ to adopt single chain nanoparticle structure.

The self-organization of POEGMA ${ }_{10 \mathrm{~K}}$ chains might arise from the interfacial energy balance between hydrophobic poly(methacrylate) backbone and hydrophilic PEG oligomer chains, and repulsion forces between the PEG oligomer chains. Degree of polymerization (DP), thus MW, affects the final molecular conformation of POEGMA since the increasing number of PEG repeating units increases the solvation effect and overall repulsion forces between PEG oligomer chains. As a result, comb-shape POEGMA offers a varying molecular conformation and intrachain self-organization behavior depending on the MW of the polymer.

Similar to our findings, Cheng and co-workers reported conformational change in OEGMA grafted polystyrene as a function of backbone length and thus amphiphilicity by using small angle neutron scattering (SANS). ${ }^{38}$ They found that polymers with low degrees of polymerization (DP) formed clusters, whereas increase in DP resulted in disappearance of clusterization. In agreement with findings of Cheng et al., Liu et al. reported that conformation of POEGMA changed from ellipsoidal to cylindrical as a function of increasing backbone length due to transition from collapsed backbone to extended backbone as a result of increased solvation effects ( $\mathrm{H}$ bonding) and flexibility. ${ }^{39,40}$

In addition to these studies, POEGMA was also reported to self-organize into mesoglobules upon heating above its LCST by Lutz and co-workers. ${ }^{41}$ However, since the experimental conditions used by Lutz and co-workers do not translate to those in this study, the self-organization behavior observed in POEGMA $_{10 \mathrm{~K}}$ cannot be attributed to mesoglobule formation.

The effect of PEG and POEGMA on cell viability and membrane permeability was investigated using BEAS-2B human lung epithelial and A549 human lung carcinoma cell lines (Figures S5 and S6) by following the protocol described in the SI. It was found that, even though both PEG and POEGMA slightly decreased the cell viability of BEAS-2B and A549 cells in a dose dependent manner, the lowest cell viability was above $50 \%$ in all cases (varying cell lines, polymer architectures and MW), indicating low cytotoxic effect of both types of polymers, in agreement with the literature. ${ }^{42}$ Interestingly, POEGMA ${ }_{20 \mathrm{~K}}$ showed more serious cytotoxicity than POEGMA PKK $_{10}$ in the A549, while the result was opposite in the BEAS-2B cell. This cell-line dependent toxicity profile of polymers may derive from differences in the cellular processes and gene expressions of these different cell lines. Additionally, neither PEG nor POEGMA was found to have an effect on the 


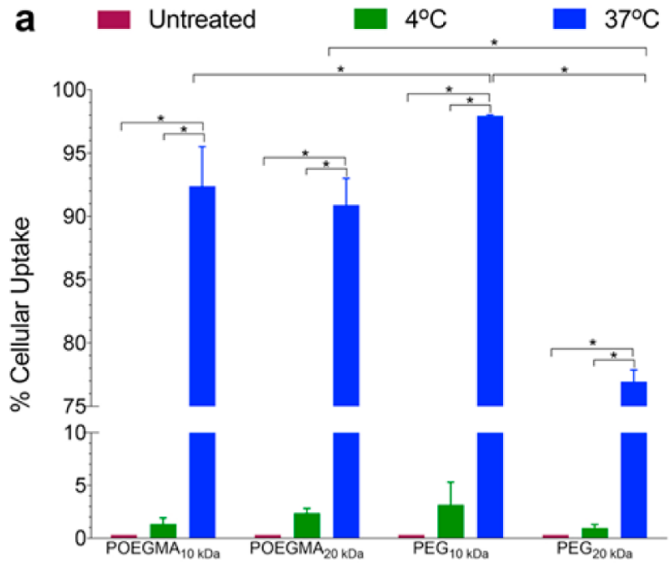

Polymer Type

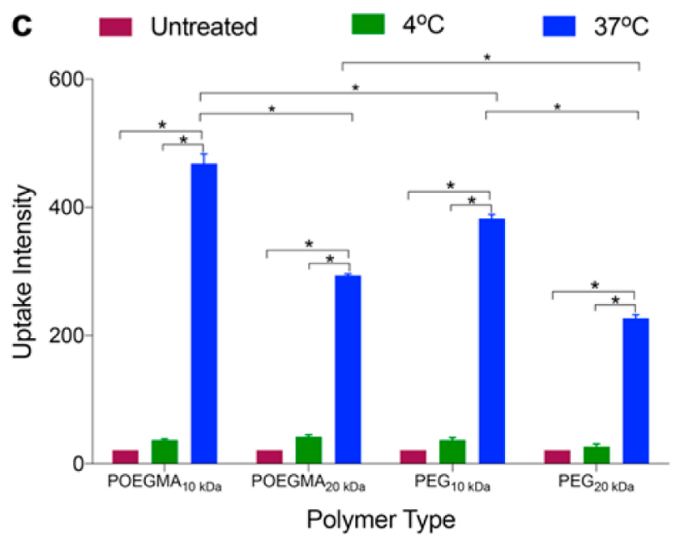

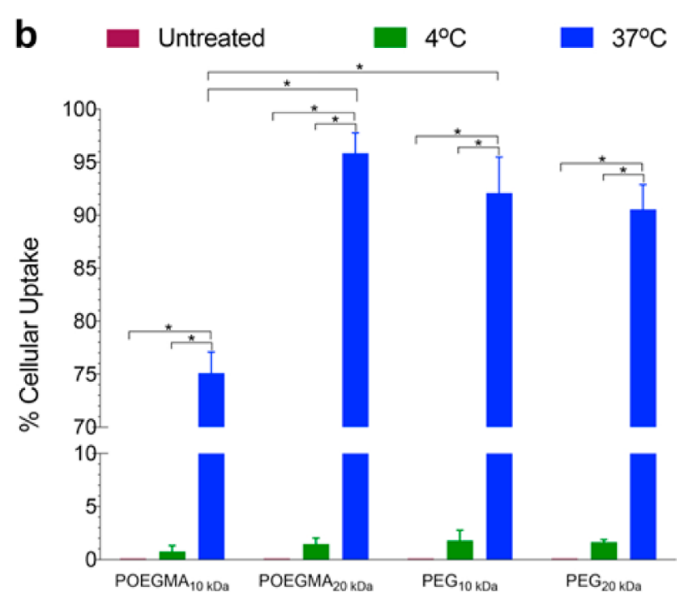

Polymer Type

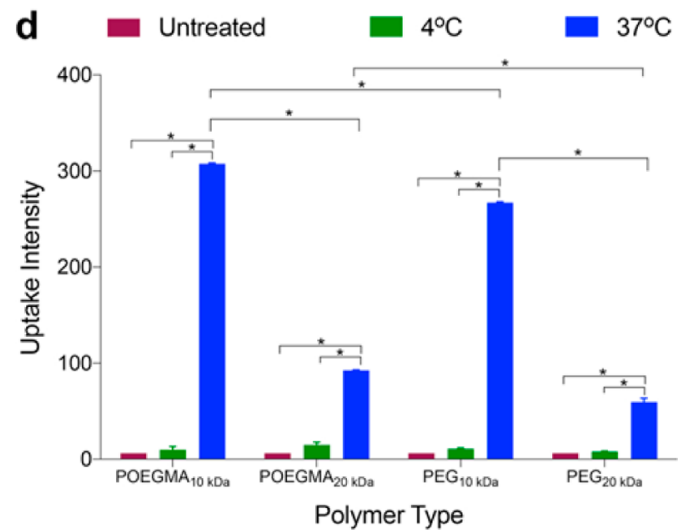

Figure 6. Energy-dependent cellular uptake of Oregon Green 488 fluorescent dye labeled POEGMAs or PEGs. Cellular uptake profile of Oregon Green 488 fluorescent dye labeled POEGMAs and PEGs by A549 cells in terms of (a) \% cellular uptake and (b) uptake intensity and that by BEAS2B cells in terms of (c) \% cellular uptake and (d) uptake intensity. The cells were incubated in the presence of Oregon Green 488 fluorescent dye labeled polymers at a concentration of $25 \mu \mathrm{M}$ for $3 \mathrm{~h}$ at either 4 or $37^{\circ} \mathrm{C}$. Data were analyzed by two-way ANOVA followed by post hoc Dunnett's multiple comparison test and plotted as mean \pm standard deviation, $n=9$; $* p<0.01$.

membrane permeability of both cell lines in consistent with the literature (Figure S5). ${ }^{22,43}$

The cellular uptake profiles of Oregon Green 488 fluorescent dye labeled PEG and POEGMA were investigated at varying temperatures $\left(4\right.$ or $\left.37^{\circ} \mathrm{C}\right)$, polymer concentrations ( 12.5 or 25 $\mu \mathrm{M})$ and incubation times ( 1 or $3 \mathrm{~h}$ ). In these experiments performed to understand how polymers interact with cells, the incubation times and polymer doses were chosen to show possible differences in the kinetics of polymer uptake levels at as short incubation times as possible to avoid saturation of cells with polymers. It is known that macromolecular architectures such as polymers, proteins and polysaccharides at similar MW range are usually taken up by energy-dependent cellular uptake mechanisms referred to as endocytosis even though there are also many exceptions reported in literature. ${ }^{25,44}$ In accord with the literature, both PEG and POEGMA were found to be taken up by both cell lines via energy-dependent mechanisms as the $\%$ cellular uptake (i.e., the ratio of the number of cells that internalize the polymer to the total number of cells) and uptake intensity (i.e., total fluorescence intensity divided by the total number of cells) values observed at $4{ }^{\circ} \mathrm{C}$ were found to be almost completely diminished compared to those at $37^{\circ} \mathrm{C}(p<$ 0.01; Figure 6).
Percentages of cellular uptake and uptake intensity of both types of Oregon Green 488 fluorescent dye labeled polymers were found to increase significantly in a polymer dose and incubation time dependent manner at $37^{\circ} \mathrm{C}$ in both cell lines studied $(p<0.05$; Figure 7$)$. Significant architecture- and MWdependent differences were observed. The POEGMA ${ }_{10 \mathrm{~K}}$ uptake intensities of both cell lines were found to be higher than or equal to the $\mathrm{PEG}_{10 \mathrm{~K}}$ uptake intensities even though the \% cellular uptake after incubation with $\mathrm{POEGMA}_{10 \mathrm{~K}}$ was lower than or equal to those observed with $\mathrm{PEG}_{10 \mathrm{~K}}$. This result suggests that POEGMA ${ }_{10 \mathrm{~K}}$ is internalized in equal or higher quantities per cell than $\mathrm{PEG}_{10 \mathrm{~K}}$. In case of polymers with 20 $\mathrm{kDa} \mathrm{MW}$, both cell lines displayed higher uptake intensity and $\%$ cellular uptake after incubation with POEGMA indicating that POEGMA ${ }_{20 \mathrm{~K}}$ is taken up by higher number of cells in higher quantities than $\mathrm{PEG}_{20 \mathrm{~K}}$. Overall results show that POEGMA, regardless of MW, is taken up in higher quantities by cells compared with the linear counterparts. The higher uptake intensity of POEGMA (per cell) than PEG was attributed to the differences in the molecular size, conformation, chemical structure and protein interactions of polymers (e.g., compact $D_{\mathrm{h}}$, amphiphilic structure, and higher serum protein-binding of POEGMA). On the other hand, the number of cells that internalize the comb-shape polymers appears to 


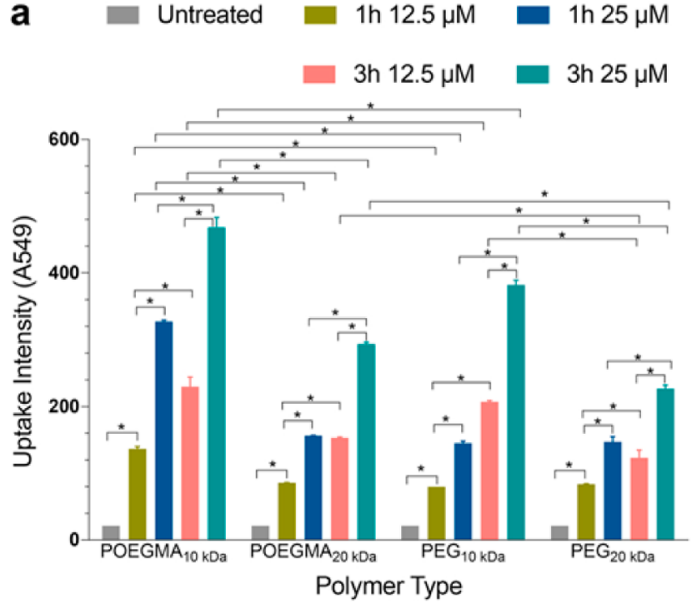

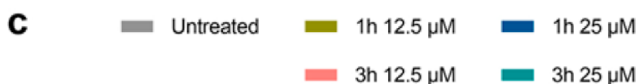

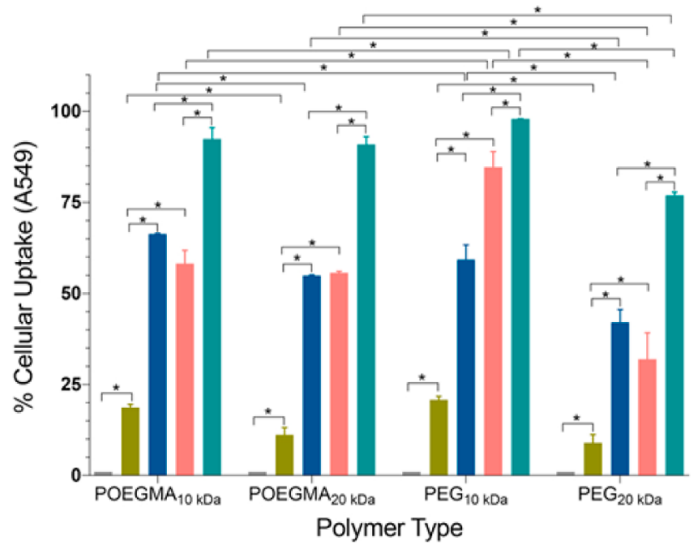

b

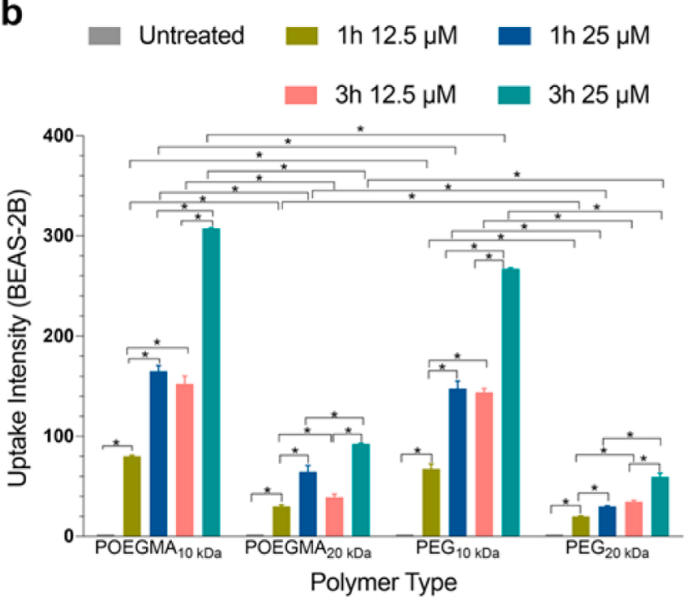

d
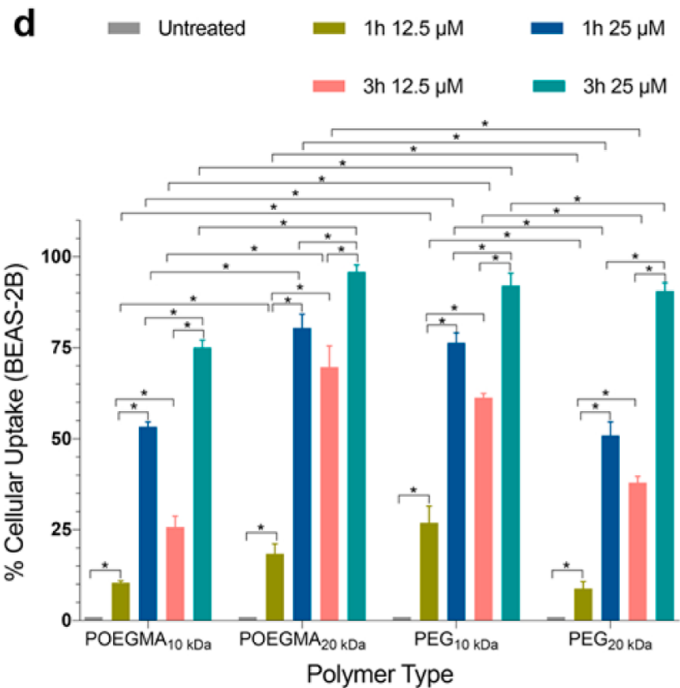

Figure 7. Dose- and time-dependent cellular uptake profile of Oregon Green 488 fluorescent dye labeled POEGMAs and PEGs in terms of uptake intensity $(\mathrm{a}, \mathrm{b})$ and \% cellular uptake $(\mathrm{c}, \mathrm{d})$. Untreated represents cells without any treatment. Data were analyzed by two-way ANOVA followed by post hoc Dunnett's multiple comparison test and plotted as mean \pm standard deviation, $n=9$; $* p<0.05$.

depend on the MW of the polymer (\% cell uptake of POEGMA $_{10 \mathrm{~K}}<\mathrm{PEG}_{10 \mathrm{~K}}$ and POEGMA $\left.20 \mathrm{~K}>\mathrm{PEG}_{20 \mathrm{~K}}\right)$. This might be due to the varying molecular conformation and selforganization behavior of comb-shape polymers depending on the MW, as confirmed by AFM data. The effect of MW of POEGMA on cellular polymer uptake was more profound in A549 lung cancer cells. Additionally, higher MW PEG was found to be uptaken by cells equal to or less than that of lower MW counterpart in both cell lines studied.

To better understand the cellular uptake profile differences between POEGMA and PEG mentioned above, the internalization mechanisms of polymers were investigated. Since it is known that cytoskeleton components play an important role in multiple cellular activities including endocytosis, ${ }^{25,45}$ the role of the two major constituents of cytoskeleton, microtubules and actin filaments, on the uptake of Oregon Green 488 fluorescent dye labeled polymers was investigated utilizing nocodazole (Noc), a microtubule depolymerization inhibitor, and cytochalasin $\mathrm{D}(\mathrm{CytD})$, an actin-disrupting agent, respectively, as transport inhibitors. The cytoskeleton components, microtubule and actin, were found to have a significant role in the uptake of PEG and POEGMA in both cell lines $(p<0.05$; Figures $8 \mathrm{a}, \mathrm{b}$ and S11). The uptake of both Oregon Green 488 fluorescent dye labeled PEG and POEGMA by A549 cells was partially inhibited in the presence of Noc, CytD, or both, suggesting that both microtubules and actin filaments were involved in the polymer uptake process. In BEAS-2B cell line, microtubules had a profound effect on the uptake of both polymer architectures whereas the role of actin filaments on Oregon Green 488 fluorescent dye labeled PEG and POEGMA internalization was found to be statistically insignificant $(p>$ $0.05)$. Overall, the results showed that the polymer architecture did not have a differential effect on the polymer internalization mediated by cytoskeleton inhibitors (vide infra).

The differences in the cellular uptake profile between linear and comb-shape polymers may be explained by possible differences in their endocytosis pathways. Clathrin-dependent (CDE) and caveolae-mediated endocytosis (CME) pathways play an active role in the polymer uptake by forming clathrin coated pits with a diameter of $100-150 \mathrm{~nm}$ or flask-shape cell membrane invaginations with a diameter of $50-100 \mathrm{~nm}$, respectively. ${ }^{46}$ The inhibition of these pathways was achieved by treating the cells with chloropromazine (CPZ) and genistein (GEN) molecules, which are known to inhibit translocation of clathrin and some adaptor proteins from cell membrane and pinching off of caveolae from the membrane via inhibition of 
a

$\square(-)$ Control $\square(+)$ Control $\square$ Noc $\square$ CytD $\square$ Noc/CytD

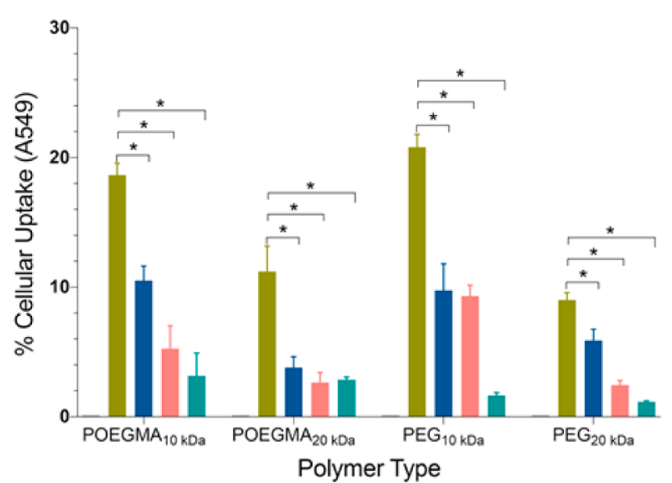

C $\square(-)$ Control $\square(+)$ Control $\square$ CPZ $\square$ Gen

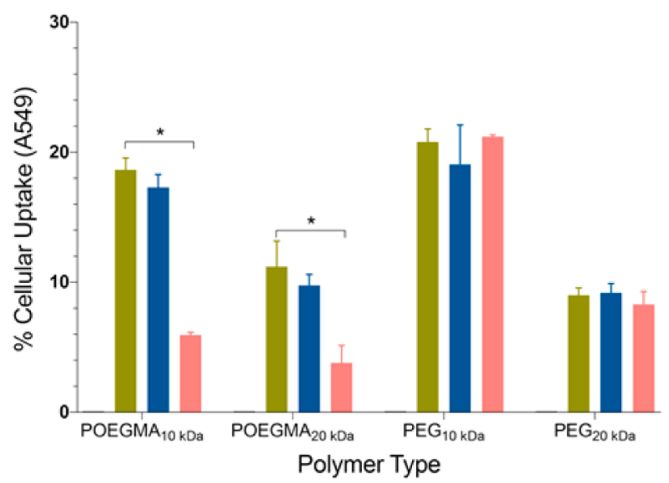

b $\square(-)$ Control $\square(+)$ Control $\square$ Noc $\square$ CytD $\square$ Noc/CytD

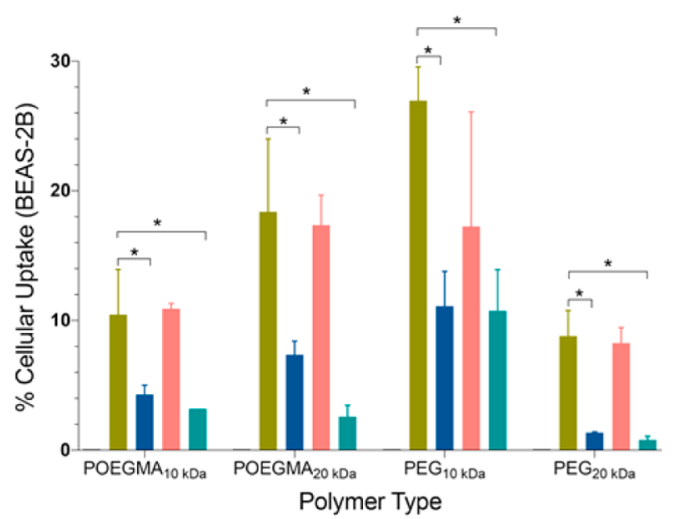

d $=(-)$ Control $\square(+)$ Control $\square \mathrm{CPZ}=$ Gen

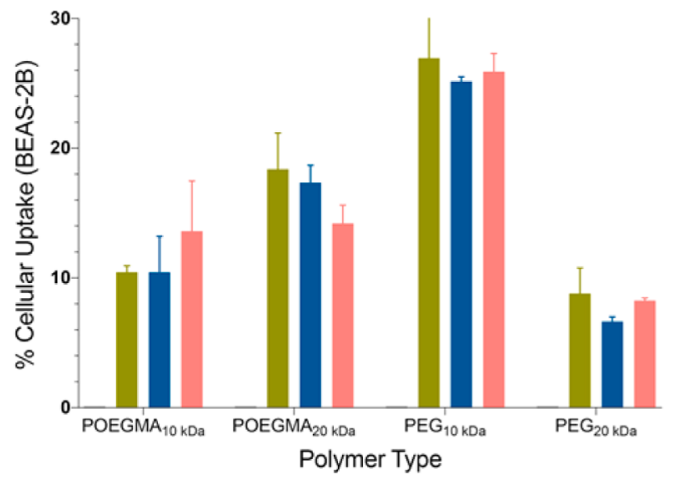

Figure 8. Cellular uptake profile of Oregon Green 488 fluorescent dye labeled POEGMAs and PEGs in the presence of cytoskeleton (a, b) and endocytosis inhibitors $(c, d)$. The $(-)$ and $(+)$ controls represent cells without any treatment and cells treated with only the given polymer in the absence of inhibitors, respectively. Data were analyzed by two-way ANOVA followed by post hoc Dunnett's multiple comparison test and plotted as mean \pm standard deviation, $n=15 ; *<0.05$.

tyrosine kinase, respectively. ${ }^{26}$ The cellular uptake of Oregon Green 488 fluorescent dye labeled POEGMAs, regardless of their molecular weight, decreased in the presence of GEN only in A549 cell line $(p<0.05)$ in contrast to the uptake of Oregon Green 488 fluorescent dye labeled PEGs, which was not affected by GEN ( $p>0.05$; Figures $8 c$,d and S11). CPZ did not inhibit the polymer uptake by A549 cells regardless of the polymer architecture $(p>0.05)$. This result shows that A549 cells differentiate the uptake route of different polymer architectures, strongly suggesting that caveoale-mediated endocytosis is one of the essential uptake routes of POEGMA, but not PEG. This differential response to polymer uptake in the presence of GEN suggests that PEG and POEGMA are internalized via different mechanisms in A549 cell line. CPZ, on the other hand, was found to have no effect on PEG or POEGMA uptake $(p>0.05)$ in both cell lines, suggesting that clathrin-dependent endocytosis is not the major uptake mechanism for both polymers. In contrast to A549 cell line, POEGMA internalization was not affected by GEN $(p>0.05)$ in BEAS-2B cell line, suggesting that cellular uptake route of POEGMA significantly depends on the cell type. Cell-line dependent internalization pathways of polymeric nanoparticles were also reported in literature supporting our findings. ${ }^{47}$ To investigate the role of macropinocytosis, which is a subtype of endocytosis, on mediating the uptake of polymers, 5-( $N$-ethyl$\mathrm{N}$-isopropyl) amiloride (EIPA), which inhibits macropinocy- tosis by lowering the submembranous $\mathrm{pH}$, was used. However, the EIPA concentration values $(>50 \mu \mathrm{M},<200 \mu \mathrm{M})$ in which macropinocytosis was inhibited, resulted in increased cell membrane permeability and reduced cell viability preventing us having a conclusion on macropinocytosis inhibition (Figure S10). Similar to our findings, the cytotoxic effects of EIPA on subset of cell lines have also been reported in literature. ${ }^{27}$ Overall, the results indicate that the CDE and CME are not the major cellular uptake mechanisms of PEG whereas the cellular uptake of POEGMA may occur through CME depending on the cell type. Additionally, higher cellular uptake and accumulation of POEGMA compared to PEG may also arise from any other unexamined internalization pathway that might occur.

The steric hindrance imposed by PEG on the conjugated biomolecules reduces cellular uptake of the specific celltargeting PEGylated systems. ${ }^{9-11}$ To reveal the possible differences between POEGMA and PEG in terms of the steric effects on the conjugated biomolecules, POEGMA ${ }_{10 \mathrm{~K}}$ and $\mathrm{PEG}_{10 \mathrm{~K}}$ were first conjugated to $\mathrm{Cy} 3$ fluorescent dye and then a cyclic pentapeptide c(Arg-Gly-Asp-D-Tyr-Cys) (cRGDyC), which is known to specifically bind to many types of integrin proteins, especially to $\alpha_{\mathrm{v}} \beta_{3}{ }^{48}$ yielding RGD-POEGMA ${ }_{10 \mathrm{~K}}-\mathrm{Cy} 3$ and RGD-PEG ${ }_{10 K}-\mathrm{Cy} 3$ (Figure 9). The degree of RGD labeling was calculated by following the protocol described in Experimental Section and given in Table S2. 


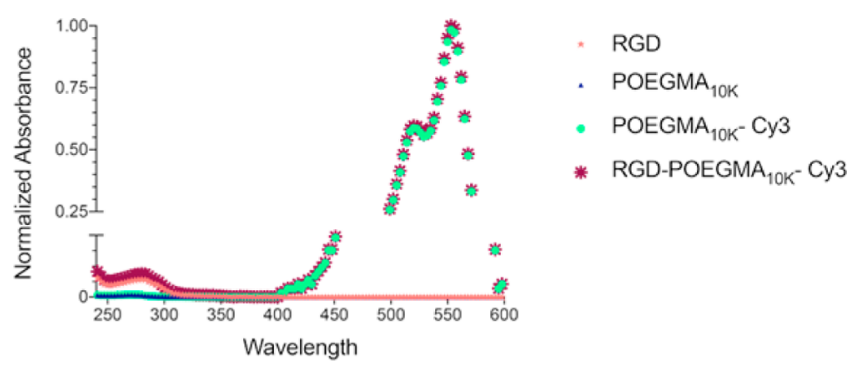

Figure 9. UV analysis of RGD conjugation to POEGMA $10 \mathrm{~K}-\mathrm{Cy}$ 3. Blue triangles (POEGMA) ${ }_{10 \mathrm{~K}}$ along with light pink stars (RGD) follow the baseline.

The uptake intensity of the RGD-POEGMA $10 \mathrm{~K}^{-\mathrm{Cy} 3}$ conjugate was found to be almost 3-fold higher compared to

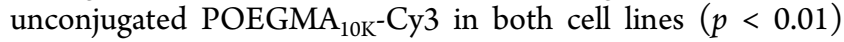
while that of RGD-PEG $10 \mathrm{~K}-\mathrm{Cy} 3$ conjugate slightly decreased in A549 and remained the same in BEAS-2B cell line when compared with the $\mathrm{PEG}_{10 \mathrm{~K}}-\mathrm{Cy} 3$ (Figure 10). Similarly, the \% cellular uptake of RGD-PEG $10 \mathrm{~K}-\mathrm{Cy} 3$ conjugate remained same while that of RGD-POEGMA $10 \mathrm{~K}-\mathrm{Cy} 3$ conjugate increased in both cell lines. These uptake profiles were attributed to lower steric hindrance imposed by POEGMA ${ }_{10 \mathrm{~K}}$ on RGD peptide compared to that by $\mathrm{PEG}_{10 \mathrm{~K}}$. Due to its more compact structure and less flexible chains, which were discussed above, POEGMA $_{10 \mathrm{~K}}$ may not hinder RGD from interacting with integrin proteins on the cell surface triggering RGD integrin binding peptide-mediated cellular uptake pathways. The PEG chains were reported to maintain their flexibility even after conjugation to proteins ${ }^{49}$ supporting our findings of higher steric hindrance imposed by linear PEG architecture compared to that by comb-shape on the conjugated biomolecules.

Similar to our findings, Ryan et al. reported that conjugation of POEGMA, which had 23 ethylene glycol unit-long pendant chains, to a small peptide, salmon calcitonin, did not result in a quite significant reduction in bioactivity. ${ }^{42}$ Zarafshani and coworkers, on the other hand, reported that trypsin-POEGMA conjugate showed higher activity than native trypsin, ${ }^{50}$ which was later attributed to hydrophobicity of POEGMA backbone, which promotes hydrophobic interactions with local environment. ${ }^{51}$ Therefore, it is possible that the hydrophobicity of backbone may be one of the parameters having a role on the lower steric hindrance impart on RGD by POEGMA in addition to its more compact structure and less flexible chains than PEG.

Interestingly, Gauthier and co-workers reported that the conformation of POEGMA, either ellipsoidal shape with collapsed backbone or cylindrical shape with extended backbone depending on the backbone length thus MW, on the surface of $\alpha$-chymotrypsin affected its bioactivity due to varying levels penetration of the substrate at different conformations of POEGMA. ${ }^{39,40}$ They also reported that conjugation of POEGMA having ellipsoidal shape due to shorter backbone to asparaginase (ASNase) yielded higher bioactivity and lower immunogenicity than that of having cylindrical shape due to longer backbone. ${ }^{40}$ Similarly, the steric hindrance imposed by POEGMA on RGD in this study may be a function of POEGMA backbone length and, thus, MW.

\section{CONCLUSION}

Collectively, our findings establish a better understanding of the utility of comb-shape POEGMA as a stealth alternative to PEG in pharmaceutical applications. These significant findings on stealth properties, molecular conformation and in vitro cell interactions of POEGMA suggest the presence of inherent differences between comb-shape and linear architectures of PEG. Future plans include establishing further conformational analysis of POEGMA to tune its in vivo properties.

\section{ASSOCIATED CONTENT}

\section{S Supporting Information}

The Supporting Information is available free of charge on the ACS Publications website at DOI: 10.1021/acs.biomac.7b00443.

Materials, ${ }^{1} \mathrm{H}$ NMR spectra of POEGMAs, ${ }^{1} \mathrm{H}$ NMR spectrum of aminolyzed POEGMA, AFM images taken at dry phase, UV-vis analysis of fluorescent dye-labeled POEGMAs and PEGs, fluorescent labeling degree of POEGMAs and PEGs, RGD conjugation degree of POEGMAs and PEGs, MTT and LDH assay experimental procedures, the effect of POEGMAs and PEGs on cell membrane permeability and cell viability, the
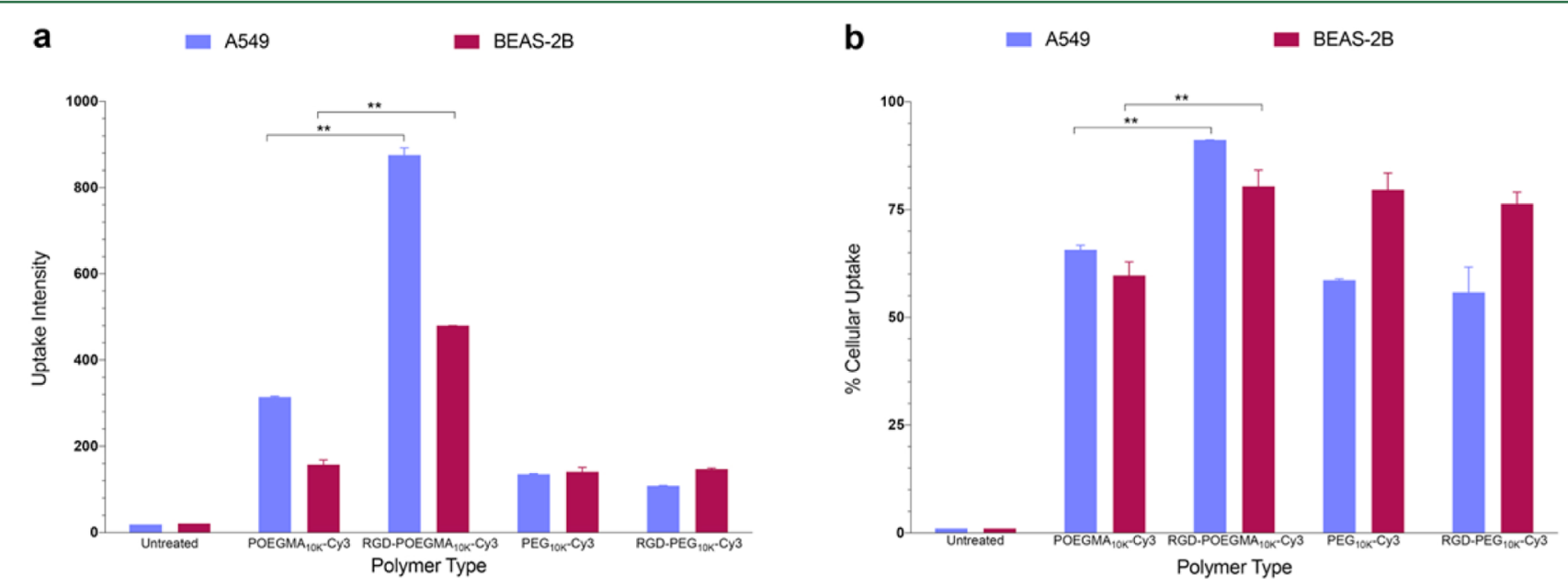

Figure 10. Cellular uptake profile of RGD-POEGMA $10 \mathrm{~K}-\mathrm{Cy} 3, \mathrm{RGD}-\mathrm{PEG}_{10 \mathrm{~K}}-\mathrm{Cy} 3, \mathrm{POEGMA}{ }_{10 \mathrm{~K}}-\mathrm{Cy} 3$, and $\mathrm{PEG}_{10 \mathrm{~K}}-\mathrm{Cy} 3$ in terms of uptake intensity (a) and \% cellular uptake (b). Untreated represents cells without any treatment. Data were analyzed by two-way ANOVA followed by post hoc Dunnett's multiple comparison test and plotted as mean \pm standard deviation, $n=9$; $* * p<0.01$. 
effect of cytoskeleton inhibitors (Noc and CytD) and endocytosis inhibitors (chlorpromazine, genistein and EIPA) on cell viability, the inhibition profiles of CDE, $\mathrm{CME}$, and macropinocytosis pathways at various concentrations of inhibitors, POEGMA and PEG uptake intensities in the presence of cytoskeleton and endocytosis inhibitors (PDF).

\section{AUTHOR INFORMATION}

\section{Corresponding Author}

*E-mail: volgabulmus@iyte.edu.tr.

ORCID

Volga Bulmus: 0000-0001-9944-1444

\section{Present Address}

${ }^{\S}$ Department of Biomedical Engineering, Duke University, Durham, NC 27708, U.S.A.

\section{Author Contributions}

I.O. and V.B. conceived and designed the research. I.O., A.T., and H.M.Z. performed experiments. Y.B. provided technical expertise and facilities for in vitro studies. I.O., A.T., and V.B. analyzed and interpreted the results. I.O. and V.B. wrote the manuscript, and H.M.Z. and Y.B. edited the manuscript. All authors discussed the results and commented on the manuscript.

Notes

The authors declare no competing financial interest.

\section{ACKNOWLEDGMENTS}

The authors acknowledge The Scientific and Technological Research Council of Turkey (TUBITAK) for financial support (113Z823) and Bioengineering Research and Application Centre (Izmir Institute of Technology, Turkey) for providing the cell culture research facilities and SPR spectroscopy.

\section{REFERENCES}

(1) Qi, Y.; Simakova, A.; Ganson, N. J.; Li, X.; Luginbuhl, K. M.; Ozer, I.; Liu, W.; Hershfield, M. S.; Matyjaszewski, K.; Chilkoti, A. brush-polymer/exendin-4 conjugate reduces blood glucose levels for up to five days and eliminates poly(ethylene glycol) antigenicity. Nat. Biomed. Eng. 2016, 1, 0002.

(2) Ozer, I.; Chilkoti, A. Site-Specific and Stoichiometric Stealth Polymer Conjugates of Therapeutic Peptides and Proteins. Bioconjugate Chem. 2017, 28 (3), 713-723.

(3) Pfister, D.; Morbidelli, M. Process for protein PEGylation. J. Controlled Release 2014, 180, 134-149.

(4) Kolate, A.; Baradia, D.; Patil, S.; Vhora, I.; Kore, G.; Misra, A. PEG - a versatile conjugating ligand for drugs and drug delivery systems. J. Controlled Release 2014, 192, 67-81.

(5) Duncan, R. The dawning era of polymer therapeutics. Nat. Rev. Drug Discovery 2003, 2, 347-360.

(6) Harris, J. M.; Chess, R. B. Effect of pegylation on pharmaceuticals. Nat. Rev. Drug Discovery 2003, 2, 214-221.

(7) Veronese, F. M.; Pasut, G. PEGylation, successful approach to drug delivery. Drug Discovery Today 2005, 10, 1451-1458.

(8) Knop, K.; Hoogenboom, R.; Fischer, D.; Schubert, U. S. Poly(ethylene glycol) in Drug Delivery: Pros and Cons as Well as Potential Alternatives. Angew. Chem., Int. Ed. 2010, 49, 6288-6308.

(9) Keefe, A. J.; Jiang, S. Poly(zwitterionic) protein conjugates offer increased stability without sacrificing binding affinity or bioactivity. Nat. Chem. 2011, 4, 59-63.

(10) Kunath, K.; Merdan, T.; Hegener, O.; Haberlein, H.; Kissel, T. Integrin targeting using RGD-PEI conjugates for in vitro gene transfer. J. Gene Med. 2003, 5, 588-599.
(11) Pelaz, B.; Del Pino, P.; Maffre, P.; Hartmann, R.; Gallego, M.; Rivera-Fernandez, S.; de la Fuente, J. M.; Nienhaus, G. U.; Parak, W. J. Surface Functionalization of Nanoparticles with Polyethylene Glycol: Effects on Protein Adsorption and Cellular Uptake. ACS Nano 2015, 9, 6996-7008.

(12) Hershfield, M. S.; Ganson, N. J.; Kelly, S. J.; Scarlett, E. L.; Jaggers, D. A.; Sundy, J. S. Induced and pre-existing anti-polyethylene glycol antibody in a trial of every 3-week dosing of pegloticase for refractory gout, including in organ transplant recipients. Arthritis Res. Ther. 2014, 16, R63.

(13) Ganson, N. J.; Kelly, S. J.; Scarlett, E.; Sundy, J. S.; Hershfield, M. S. Control of hyperuricemia in subjects with refractory gout, and induction of antibody against poly(ethylene glycol) (PEG), in a phase I trial of subcutaneous PEGylated urate oxidase. Arthritis Res. Ther. 2006, 8 , R12.

(14) Armstrong, J. K.; Hempel, G.; Koling, S.; Chan, L. S.; Fisher, T.; Meiselman, H. J.; Garratty, G. Antibody against poly(ethylene glycol) adversely affects PEG-asparaginase therapy in acute lymphoblastic leukemia patients. Cancer 2007, 110, 103-111.

(15) Ganson, N. J.; Povsic, T. J.; Sullenger, B. A.; Alexander, J. H.; Zelenkofske, S. L.; Sailstad, J. M.; Rusconi, C. P.; Hershfield, M. S. Preexisting anti-polyethylene glycol antibody linked to first-exposure allergic reactions to pegnivacogin, a PEGylated RNA aptamer. J. Allergy Clin. Immunol. 2016, 137, 1610-1613e7.

(16) Garay, R. P.; El-Gewely, R.; Armstrong, J. K.; Garratty, G.; Richette, P. Antibodies against polyethylene glycol in healthy subjects and in patients treated with PEG-conjugated agents. Expert Opin. Drug Delivery 2012, 9, 1319-1323.

(17) Richter, A. W.; Akerblom, E. Polyethylene glycol reactive antibodies in man: titer distribution in allergic patients treated with monomethoxy polyethylene glycol modified allergens or placebo, and in healthy blood donors. Int. Arch. Allergy Immunol. 2004, 74, 36-39.

(18) Gao, W.; Liu, W.; Mackay, J. A.; Zalutsky, M. R.; Toone, E. J.; Chilkoti, A. In situ growth of a stoichiometric PEG-like conjugate at a protein's N-terminus with significantly improved pharmacokinetics. Proc. Natl. Acad. Sci. U. S. A. 2009, 106, 15231-15236.

(19) Gao, W.; Liu, W.; Christensen, T.; Zalutsky, M. R.; Chilkoti, A. In situ growth of a PEG-like polymer from the $\mathrm{C}$ terminus of an intein fusion protein improves pharmacokinetics and tumor accumulation. Proc. Natl. Acad. Sci. U. S. A. 2010, 107, 16432-16437.

(20) Gunasekaran, K.; Nguyen, T. H.; Maynard, H. D.; Davis, T. P.; Bulmus, V. Conjugation of siRNA with Comb-Type PEG Enhances Serum Stability and Gene Silencing Efficiency. Macromol. Rapid Commun. 2011, 32, 654-659.

(21) Heredia, K. L.; Nguyen, T. H.; Chang, C.-W.; Bulmus, V.; Davis, T. P.; Maynard, H. D. Reversible siRNA-polymer conjugates by RAFT polymerization. Chem. Commun. (Cambridge, U. K.) 2008, 3245-3247.

(22) Pissuwan, D.; Boyer, C.; Gunasekaran, K.; Davis, T. P.; Bulmus, V. In vitro cytotoxicity of RAFT polymers. Biomacromolecules 2010, $11,412-420$

(23) Boyer, C.; Granville, A.; Davis, T. P.; Bulmus, V. Modification of RAFT-polymers via thiol-ene reactions: A general route to functional polymers and new architectures. J. Polym. Sci., Part A: Polym. Chem. 2009, 47, 3773-3794.

(24) Boyer, C.; Bulmus, V.; Davis, T. P.; Ladmiral, V.; Liu, J.; Perrier, S. Bioapplications of RAFT Polymerization. Chem. Rev. (Washington, DC, U. S.) 2009, 109, 5402-5436.

(25) Vercauteren, D.; Vandenbroucke, R. E.; Jones, A. T.; Rejman, J.; Demeester, J.; De Smedt, S. C.; Sanders, N. N.; Braeckmans, K. The Use of Inhibitors to Study Endocytic Pathways of Gene Carriers: Optimization and Pitfalls. Mol. Ther. 2010, 18, 561-569.

(26) Sevimli, S.; Sagnella, S.; Macmillan, A.; Whan, R.; Kavallaris, M.; Bulmus, V.; Davis, T. P. The endocytic pathway and therapeutic efficiency of doxorubicin conjugated cholesterol-derived polymers. Biomater. Sci. 2015, 3, 323-335.

(27) Commisso, C.; Flinn, R. J.; Bar-Sagi, D. Determining the macropinocytic index of cells through a quantitative image-based assay. Nat. Protoc. 2014, 9, 182-192. 
(28) Cseke, G.; Maginnis, M. S.; Cox, R. G.; Tollefson, S. J.; Podsiad, A. B.; Wright, D. W.; Dermody, T. S.; Williams, J. V. Integrin alphavbetal promotes infection by human metapneumovirus. Proc. Natl. Acad. Sci. U. S. A. 2009, 106, 1566-1571.

(29) Odrljin, T. M.; Haidaris, C. G.; Lerner, N. B.; Simpson-Haidaris, P. J. Integrin alphavbeta3-mediated endocytosis of immobilized fibrinogen by A549 lung alveolar epithelial cells. Am. J. Respir. Cell Mol. Biol. 2001, 24, 12-21.

(30) Fox, M. E.; Szoka, F. C.; Frechet, J. M. Soluble polymer carriers for the treatment of cancer: the importance of molecular architecture. Acc. Chem. Res. 2009, 42, 1141-1151.

(31) Alexis, F.; Pridgen, E.; Molnar, L. K.; Farokhzad, O. C. Factors affecting the clearance and biodistribution of polymeric nanoparticles. Mol. Pharmaceutics 2008, 5, 505-515.

(32) Singh, Y.; Gao, D.; Gu, Z.; Li, S.; Stein, S.; Sinko, P. J. NonInvasive Detection of Passively Targeted Poly(ethylene glycol) Nanocarriers in Tumors. Mol. Pharmaceutics 2012, 9, 144-155.

(33) Gibson, M. I.; Paripovic, D.; Klok, H. A. Size-Dependent LCST Transitions of Polymer-Coated Gold Nanoparticles: Cooperative Aggregation and Surface Assembly. Adv. Mater. (Weinheim, Ger.) 2010, 22, 4721-4725.

(34) Lutz, J.-F.; Akdemir, Ö.; Hoth, A. Point by Point Comparison of Two Thermosensitive Polymers Exhibiting a Similar LCST: Is the Age of Poly(NIPAM) Over? J. Am. Chem. Soc. 2006, 128, 13046-13047.

(35) Yeh, P.Y. J.; Kainthan, R. K.; Zou, Y.; Chiao, M.; Kizhakkedathu, J. N. Self-Assembled Monothiol-Terminated Hyperbranched Polyglycerols on a Gold Surface: A Comparative Study on the Structure, Morphology, and Protein Adsorption Characteristics with Linear Poly(ethylene glycol)s. Langmuir 2008, 24, 4907-4916.

(36) Raposo, M.; Ferreira, Q.; Ribeiro, P. In Modern Research and Educational Topics in Microscopy: A Guide for Atomic Force Microscopy Analysis of Soft Condensed Matter; Méndez-Vilas, A., Díaz, J., Eds.; Formatex: Spain, 2007; Vol. 2, pp 758-769.

(37) Winzer, A. T.; Kraft, C.; Bhushan, S.; Stepanenko, V.; Tessmer, I. Correcting for AFM tip induced topography convolutions in protein-DNA samples. Ultramicroscopy 2012, 121, 8-15.

(38) Cheng, G.; Melnichenko, Y. B.; Wignall, G. D.; Hua, F.; Hong, K.; Mays, J. W. Small Angle Neutron Scattering Study of Conformation of Oligo(ethylene glycol)-Grafted Polystyrene in Dilute Solutions: Effect of the Backbone Length. Macromolecules (Washington, DC, U. S.) 2008, 41, 9831-9836.

(39) Liu, M.; Tirino, P.; Radivojevic, M.; Phillips, D. J.; Gibson, M. I.; Leroux, J. C.; Gauthier, M. A. Molecular Sieving on the Surface of a Protein Provides Protection Without Loss of Activity. Adv. Funct. Mater. 2013, 23, 2007-2015.

(40) Liu, M.; Johansen, P.; Zabel, F.; Leroux, J. C.; Gauthier, M. A. Semi-permeable coatings fabricated from comb-polymers efficiently protect proteins in vivo. Nat. Commun. 2014, 5, 5526-5534.

(41) Lutz, J.-F.; Weichenhan, K.; Akdemir, Ö.; Hoth, A. About the Phase Transitions in Aqueous Solutions of Thermoresponsive Copolymers and Hydrogels Based on 2-(2-methoxyethoxy)ethyl Methacrylate and Oligo(ethylene glycol) Methacrylate. Macromolecules (Washington, DC, U. S.) 2007, 40, 2503-2508.

(42) Ryan, S. M.; Wang, X.; Mantovani, G.; Sayers, C. T.; Haddleton, D. M.; Brayden, D. J. Conjugation of salmon calcitonin to a combedshaped end functionalized poly(poly(ethylene glycol) methyl ether methacrylate) yields a bioactive stable conjugate. J. Controlled Release 2009, 135, 51-59.

(43) Hong, S. P.; Leroueil, P. R.; Janus, E. K.; Peters, J. L.; Kober, M. M.; Islam, M. T.; Orr, B. G.; Baker, J. R.; Holl, M. M. B. Interaction of polycationic polymers with supported lipid bilayers and cells: Nanoscale hole formation and enhanced membrane permeability. Bioconjugate Chem. 2006, 17, 728-734.

(44) Zeng, X.; Zhang, Y.; Nystrom, A. M. Endocytic uptake and intracellular trafficking of bis-MPA-based hyperbranched copolymer micelles in breast cancer cells. Biomacromolecules 2012, 13, 38143822.

(45) dos Santos, T.; Varela, J.; Lynch, I.; Salvati, A.; Dawson, K. A. Effects of Transport Inhibitors on the Cellular Uptake of Carboxylated
Polystyrene Nanoparticles in Different Cell Lines. PLoS One 2011, 6, e24438.

(46) Kim, J.; Sunshine, J. C.; Green, J. J. Differential Polymer Structure Tunes Mechanism of Cellular Uptake and Transfection Routes of Poly ( $\beta$-amino ester) Polyplexes in Human Breast Cancer Cells. Bioconjugate Chem. 2014, 25, 43-51.

(47) Douglas, K. L.; Piccirillo, C. A.; Tabrizian, M. Cell linedependent internalization pathways and intracellular trafficking determine transfection efficiency of nanoparticle vectors. Eur. J. Pharm. Biopharm. 2008, 68, 676-687.

(48) Yu, Y. P.; Wang, Q.; Liu, Y. C.; Xie, Y. Molecular basis for the targeted binding of RGD-containing peptide to integrin alphaVbeta3. Biomaterials 2014, 35, 1667-1675.

(49) $\mathrm{Mu}, \mathrm{Q}$; $\mathrm{Hu}, \mathrm{T}$.; Yu, J. Molecular Insight into the Steric Shielding Effect of PEG on the Conjugated Staphylokinase: Biochemical Characterization and Molecular Dynamics Simulation. PLoS One 2013, 8, e68559.

(50) Zarafshani, Z.; Obata, T.; Lutz, J.-F. Smart PEGylation of Trypsin. Biomacromolecules 2010, 11, 2130-2135.

(51) Liu, M.; Leroux, J. C.; Gauthier, M. A. Conformation-function relationships for the comb-shaped polymer pOEGMA. Prog. Polym. Sci. 2015, 48, 111-121. 